United States Department of Commerce

Technology Administration

National Institute of Standards and Technology

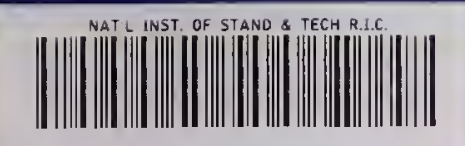

\section{Al2103 733652}

NIST

PUELICATIONS

NIST Special Publication 830

\title{
The Manufacturing Technology Centers Program
} A Sampling of Individual Case Histories

Richard Suenram 



\title{
NIST Special Publication 830
}

\section{The Manufacturing Technology Centers Program A Sampling of Individual Case Histories}

\author{
Richard Suenram \\ Manufacturing Engineering Laboratory \\ National Institute of Standards and Technology \\ Gaithersburg, MD 20899
}

February 1992

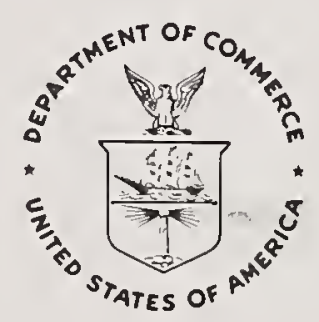

U.S. Department of Commerce

Rockwell A. Schnabel, Acting Secretary

Technology Administration

Robert M. White, Under Secretary for Technology

National Institute of Standards and Technology

John W. Lyons, Director 
National Institute of Standards and Technology Special Publication 830 Natl. Inst. Stand. Technol. Spec. Publ. 830 25 pages (Feb. 1992)
U.S. Government Printing Office Washington: 1992
For sale by the Superintendent of Documents U.S. Government Printing Office Washington, DC 20402 


\section{CONTENTS}

THE MANUFACTURING TECHNOLOGY CENTERS PROGRAM . . . . . . . . . . . . . . . 1

Northeast Manufacturing Technology Center, Troy, NY .................... 1

Southeast Manufacturing Technology Center, Columbia, SC .................... 2

Great Lakes Manufacturing Technology Center, Cleveland, $\mathrm{OH} \ldots \ldots \ldots \ldots \ldots \ldots \ldots \ldots$

Midwest Manufacturing Technology Center, Ann Arbor, MI .................... 2

Mid-America Manufacturing Technology Center, Overland Park, KS .............. 2

A SAMPLING OF INDIVIDUAL CASE HISTORIES $\ldots \ldots \ldots \ldots \ldots \ldots \ldots \ldots \ldots \ldots \ldots \ldots \ldots$

UNICO Special Products, Beacon, NY . . . . . . . . . . . . . . . . . . . . . . 3

Newburgh Metalizing Corporation, Newburgh, NY..................... 5

Brimfield Precision Inc., Brimfield, MA ........................... 7

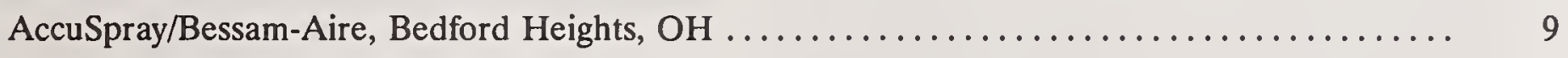

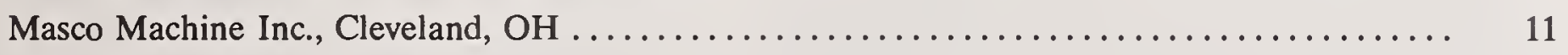

STERIS Corporation, Mentor, OH. ............................ 13

Roller Bearing Company of America, Hartsville, SC ........................ 14

Carolina Equipment and Supply Company Inc., Charleston, SC . . . . . . . . . . . . . 16

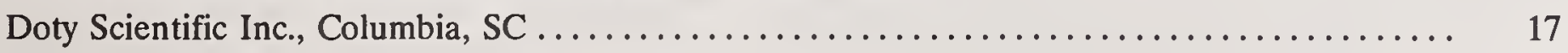

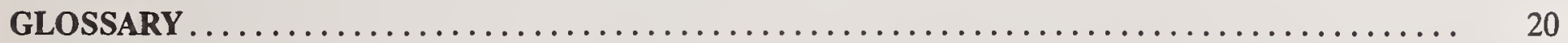





\section{The Manufacturing Technology Centers Program}

The United States' long-dominant position in the world's marketplace is declining due to increasingly sophisticated foreign competition and the swiftness of changing technologies. There are more than 350,000 manufacturing firms in the U.S. with less than 500 employees. These firms employ 12 million workers and account for over $50 \%$ of the total of this country's value added to goods and services. While many small manufacturing firms have been able to maintain their competitive edge in smaller domestic markets and in special technology areas, they simply have not kept pace with the rapidly changing, computer-driven, global marketplace of the past decade.

To address this problem, the Omnibus Trade and Competitiveness Act established the Manufacturing Technology Centers (MTC) program as a new initiative at the National Institute of Standards and Technology (NIST). The charge of the program was to contribute toward improved U.S. industrial productivity and competitiveness in the growing international marketplace.

In January of 1989 three centers were established. These were the Northeast Manufacturing Technology Center (NEMTC) located in Troy, New York, the Great Lakes Manufacturing Technology Center (GLMTC) based in Cleveland, Ohio, and the Southeast Manufacturing Technology Center (SMTC), situated in Columbia, South Carolina. Since beginning operation in 1989 , these three centers have achieved an estimated cost savings of more than $\$ 130$ million for the more than 6000 small business firms that they have assisted.

In the spring of 1991 two new centers were established. They are the Mid-America Manufacturing Technology Center (MAMTC) located in Kansas City, Kansas, and the Midwest Manufacturing Technology Center (MMTC) in Ann Arbor, Michigan.

The centers are designed to bridge a technology gap between sources of manufacturing technology and the small and mid-sized companies that need it. Sources of technology consist of a number of Government research and development laboratories, universities, and other research-oriented organizations as well as commercial sources. Although the basic charge to each center is the same, "to transfer advanced manufacturing technologies to small and medium sized manufacturers to improve their competitive position," each center's approach is unique, tempered in many respects by the locale and the type of manufacturing firms being assisted.
The centers provide a wide range of services including individual project engineering, training courses, demonstrations, and assistance in selecting and using software and equipment. All centers have established large data bases of computeraided design (CAD) and computer-aided manufacturing (CAM) software packages as well as a wide variety of PC-based hardware systems, workstations, and mini-computers which use the software. This provides small manufacturers an extensive selection of state-of-the-art systems with which they can gain hands-on experience. This allows them to make intelligent decisions on the system selection that is best suited for their application. In addition to the computer demonstration facilities, the centers also have demonstration facilities which display various types of automated metal working equipment (lathes and milling machines), robotics, and state-of-the-art coordinate measuring machines which are used to demonstrate the automated machining process. Two of the centers (NEMTC in New York and MAMTC in Kansas) have mobile demonstration facilities under construction which will allow demonstrations of automated equipment at some of the more remote manufacturing firms, technology symposia, and other events. These types of facilities should be extremely useful where larger territories are being served. Some aspects of the individual centers are highlighted below:

\section{Northeast Manufacturing Technology Center, Troy, NY}

The Northeast Manufacturing Technology Center is located within the Center for Manufacturing Productivity and Technology Transfer on the Rensselaer Polytechnic Institute campus in Troy, New York. NEMTC's principal target region is New York State ( $81 \%$ of client interactions) with some satellite operations in Massachusetts (12\%), Pennsylvania (5\%), and Maine (1\%). Their typical client firms have $25-75$ employees and fall into Standard Industrial Classification (SIC) 3400 (Fabricated Metal Products) and SIC 3500 (Industrial Machinery and Equipment). NEMTC is strongly tied into the highly developed outreach program provided by the New York State Science and Technology Foundation Industrial Technology Extension Service. In addition, the Hudson Valley Community College also located in Troy, New York, serves as 
NEMTC's liaison with a network of community colleges located throughout the Northeast. During 1990 NEMTC initiated 68 field projects with small manufacturing firms in this region.

\section{Southeast Manufacturing Technology Center, Columbia, SC}

The Southeast Manufacturing Technology Center is located on the campus of the University of South Carolina in Columbia, South Carolina. SMTC's client base are the $4000+$ small- and medium-sized manufacturing firms in the state. Typical client firms have 50-100 employees. Most of the target firms are small rural manufacturers of discrete parts and metalworking firms with a smaller number specializing in electrical/electronic, plastics, and lumber/ wood products. SMTC's emphasis on technology transfer is coordinated through the technical colleges throughout the state with primary centers located at Greenville Technical College in Greenville, Midlands Technical College in Columbia, and Trident Technical College in Charleston. The SMTC has worked with 331 firms in technology transfer projects.

\section{Great Lakes Manufacturing Technology Center, Cleveland, $\mathbf{O H}$}

The Great Lakes Manufacturing Technology Center (GLMTC) was established by the Cleveland Advanced Manufacturing Program (CAMP). CAMP is a 501(c)(3) not-for-profit company incorporated in $\mathrm{Oh}$

0 and headquartered in Cleveland. CAMP is part of the state of Ohio's eight-center Edison Technology Center network. GLMTC's client base are the nearly 9000 manufacturing establishments in and around the Cleveland area. The more general region served, however, ranges from Minnesota to Pennsylvania in the Great Lakes area. The GLMTC serves this extended region through a network of affiliated centers known as the Association of Great Lakes Manufacturing Support Centers. Nearly $40 \%$ of the firms served by the GLMTC are SICs 3400 (Fabricated Metal Products) and 3500 (Industrial Machinery and Equipment) with the remaining firms being a diverse cross section of manufacturing technologies. Approximately $90 \%$ of the firms have less than 100 employees. During 1990 GLMTC initiated 334 technology transfer projects for 197 firms in this region.

\section{Midwest Manufacturing Technology Center, Ann Arbor, MI}

The Midwest Manufacturing Technology Center (MMTC) was founded as a part of the Industrial Technology Institute (ITI) located in Ann Arbor, Michigan. The initial service area for MMTC is the southern Michigan region which has approximately 4000 manufacturing firms with 800,000 employees. Two of the core industries in Michigan are automobile production and office furniture manufacturing. One third of all auto industries (SICs 3711 and 3714 ) employment is in Michigan. In addition, $40 \%$ of office furniture (SIC 2522) manufacturing is done in Michigan. Initially, MMTC plans to concentrate its efforts on the small firms that supply automotive manufacturers and metal office furniture companies. These firms specialize in machine tools, tooling, metal forming, and plastic processing.

\section{Mid-America Manufacturing Technology Center, Overland Park, KS}

The Mid-America Manufacturing Technology Center (MAMTC) located in Overland Park, Kansas, is a subsidiary of Kansas Technology Enterprise Corporation (KTEC) which is headquartered in Topeka, Kansas. KTEC is a non-profit corporation established by the state of Kansas. The service area of MAMTC is the entire state of Kansas and several adjoining counties of Missouri near Kansas City. This area contains more than 2600 small to medium manufacturing firms. There is a diverse mix of urban and rural manufacturing establishments. The three largest industry groups manufacture agricultural equipment, fabricated metal products and aircraft parts. In addition to the Overland Park headquarters for MAMTC, six regional technology transfer offices are located throughout the state, with a seventh planned for the Kansas City, Missouri, area. MAMTC also has strong ties to the colleges and vocational technical institutes in the state. 


\section{A Sampling of Individual Case Histories}

The following descriptions of interactions that the Manufacturing Technology Centers have had with a number of firms in their respective regions were selected to reflect the wide variety of assistance that the MTCs can provide to client firms. Some of the interactions are quite basic in nature, ranging from simple CAD/CAM selection and implementation to several interactions that were unique, providing a definite challenge to the staffs of the MTCs involved.

\section{UNICO Special Products, Beacon, NY}

UNICO Special Products is a small manufacturing firm of 27 employees that has been in business for approximately 20 years. In 1990 they had sales revenues of $\$ 2-\$ 3$ million. It is located on the East bank of the Hudson river in Beacon, New York, a small town about one-hour's travel time north of New York City. It specializes in high-end, custommade countertops for kitchens and baths as well as custom-made shower enclosures. Most of the custom-made countertops are constructed from products like Corian ${ }^{1}$ by DuPont, Surell by Formica and Fountainhead by Nevamar. Unlike less expensive countertop construction which consists of some form of laminated materials, these acrylic materials are composed of a solid sheet of acrylic and natural minerals that has the look and feel of stone or granite. In addition to the pleasing aesthetic characteristics of the materials, they have a nice feature from a manufacturing standpoint in that they can be machined using conventional woodworking techniques and tools. One minor drawback to the acrylic materials is that they are moderately expensive, costing from $\$ 300$ to $\$ 800$ per sheet. It is thus necessary to keep waste and miscuts to an absolute minimum.

UNICO is a regional supplier that services primarily the New York City area along with some parts of northern New Jersey. Typically UNICO manufactures countertops for approximately 20 kitchens and baths per week (60-80 countertops). Customers are served through a network of retail outlets. Customers provide drawings of the custom countertops to be fabricated, and UNICO manufactures the products according to the

\footnotetext{
${ }^{1}$ Throughout this publication certain companies, commercial equipment, instruments, or materials are identified in order to adequately describe the situation being discussed. Such identification does not imply recommendation or endorsement by the National Institute of Standards and Technology, nor does it imply that the items being referred to are necessarily the best available for the purpose.
}

specifications provided by the customers through the retail outlets. As might be expected, in addition to providing a quality custom-built product, short turnaround time is often necessary to assure customer satisfaction.

In 1989 UNICO purchased a Shoda five-head, computer-numeric-controlled (CNC) router system for $\$ 250,000$ and a personal computer (PC) based Computer-Aided Design/Computer-Aided Manufacturing (CAD/CAM) system which they hoped would address both the quality product factor and shorten turnaround time for their custom countertops and other products made from acrylic materials. The router allows five different tool setups to be configured at one time. It can then be programmed to carry out a number of machining functions on a given workpiece. The router's design makes it extremely convenient for repetitive machining batch-size lots of any given piece using only one computer setup. UNICO managers realized that the particular application they had for the machine was not exactly what the machine was designed for, but using this new technology would provide substantial benefits in a number of areas. UNICO wanted to use the computer-controlled router to completely cut out their product

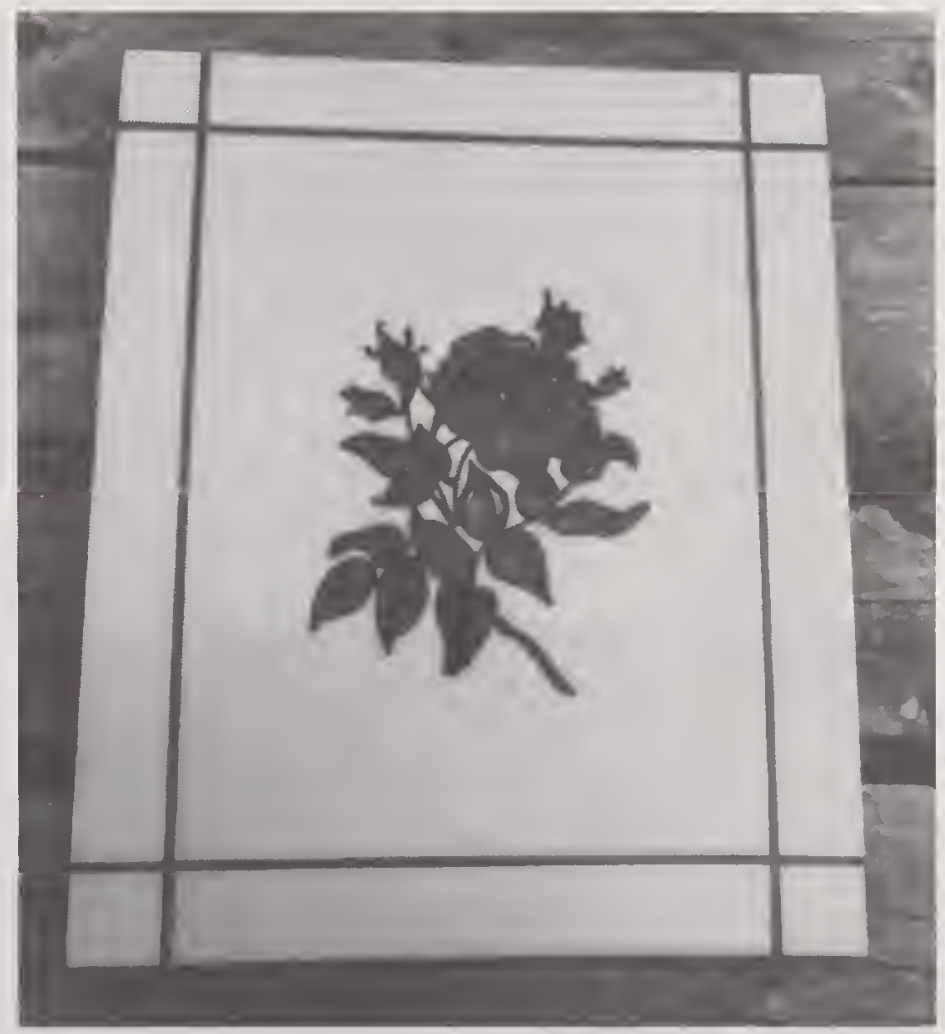

Figure 1. Rose inlay created by routing out a pattern in the acrylic countertop material and then filling with material that is usually used to make repairs in the countertop materials. This illustrates the versatility of the computer-controlled router for making complex shapes. 
specialty, custom countertops. The bed of the router facility was large enough to accommodate large sheets of the acrylic materials and, using the appropriate computer commands, the finished countertop could be machined in a single process without ever having to move it from the router work bed. UNICO found that the final product produced in this fashion was far superior to the ones produced using previous manufacturing techniques which employed a large manual panel-saw type setup. The improved process yielded a custom countertop that was precisely machined to within 80 to $100 \mu \mathrm{m}$ (a few thousandths of an inch) of the original specifications. In addition, the smooth finish obtained using the computer-controlled router eliminated a costly and time-consuming final finish sanding of many of the machined edges. The precisely machined straight edges of the countertops allowed much nicer glue joints to be obtained, producing a finished joint that was nearly invisible to the naked eye. It also facilitated the use of intricate, decorative inlays in the countertops that would have been extremely difficult or nearly impossible using manual construction techniques.

A major problem that UNICO encountered was that it was taking as long as 30 to 45 minutes to program the router to carry out the machining operations for every countertop. Since every countertop was a one-of-a-kind custom built unit, every one had to be programmed into the computer. Because of this, UNICO was not utilizing the computerized router to its maximum capabilities, in fact for some more complicated setups, it was still faster to manufacture the countertop using the router directly without the computer driving it. UNICO contacted NEMTC and asked if the staff at NEMTC could find a solution to their programming problem. Their goal was to reduce lead time from order-to-delivery from three weeks to less than one week. The problem was referred to Frank Raymond of Hudson Valley Community College in Troy, New York. Frank is a CAM programming specialist at Hudson Valley. After visiting UNICO

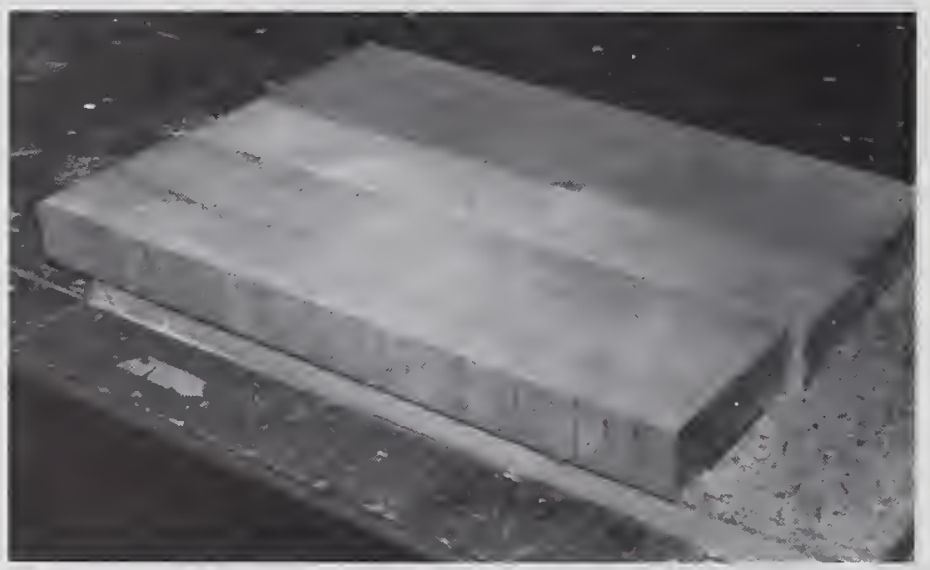

and studying their problem, he was able to write a series of macro programs which employ numerous default parameters that will automatically be invoked in the manufacturing process unless changed during the programming sequence. This has reduced the time necessary for programming the computer for an individual countertop to ten minutes instead of the original 45 . This now allows UNICO to manufacture all of its custom-built countertops on the router. The new process is much faster than the old one which it replaces. UNICO has reduced its turnaround time from three weeks to several days. Because of this the firm has been able to retain its $85 \%$ market share of the work in its territory. The impact of this project on UNICO is estimated to be $\$ 200,000$.

According to Joe Guarneri, UNICO sales manager, the firm is now receiving a number of its customer orders in form of full-scale working patterns instead of engineering drawings. This presents an additional problem for UNICO since it must first convert the pattern to computer format and then machine the final product which should match the working pattern. Unfortunately, this puts the company back into the situation it had originally in that it takes longer to convert the pattern dimensions into computer format than it would to just lay the pattern on a sheet of the acrylic and use the router directly without the computer driving it to manufacture the countertop. UNICO has again asked for assistance from Frank Raymond on tackling this problem, and Frank is currently studying the situation.

As is often the case for a large automated machine, the more it is utilized the more economical it becomes. In an effort to increase the use time of the machine, UNICO is now taking on additional work for the router to fill in slack time in which the router is not being used for custom countertop production. UNICO is currently using the router to manufacture a number of different types of products. One such project involves the machining of electric guitar bodies for a leading electric guitar

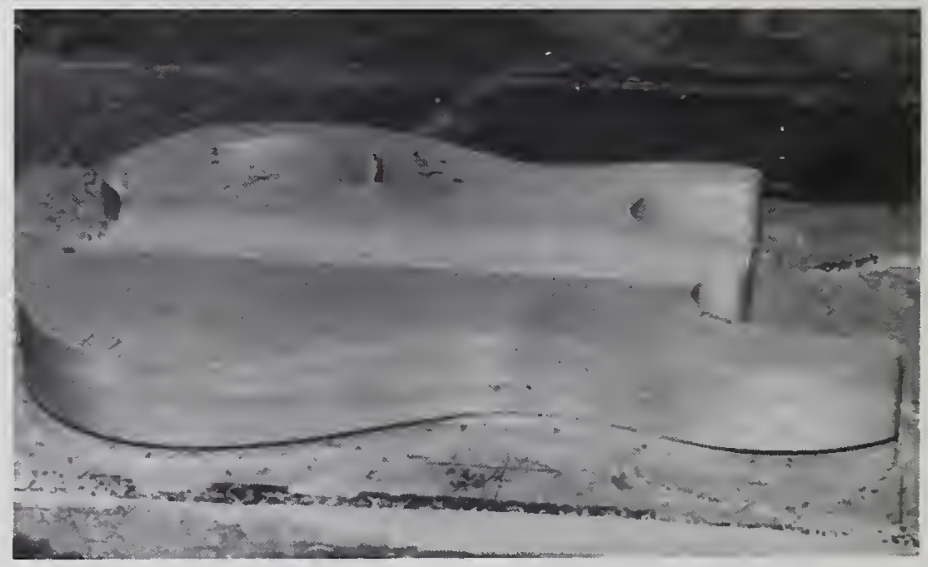

Figure 2. Electric guitar body, before (left) and after the first pass with the computer-controlled router. 
manufacturer. This is the type of project that the router was designed to accomplish; i.e., using one computer program, numerous guitar bodies can be produced daily. UNICO now has a standing order for 200 guitar bodies per month. The guitar bodies are cut from a solid block of hard maple in a twostep process using one set of router bits. In the first step, all machining operations are performed on one side of the guitar body; the body is then turned over and located on the router table with holes that were cut in the first side. All machining operations on the second side can then be completed. The whole process takes only a few minutes, and each body is an exact duplicate. This precise machining also makes the later stages of the guitar construction much easier.

\section{Newburgh Metalizing Corporation, Newburgh, NY}

Newburgh Metalizing Corporation is a new firm founded in 1990 which is closely affiliated with Newburgh Molded Products, a manufacturer of plastic perfume and cosmetic bottle caps. Both firms are located in Newburgh, New York, approximately 50 miles north of the New York City area along the Hudson River. Newburgh Molded Products (NMP), an injection molding company, was established in 1975. A sister company, Foster Forbes, in Marion, Indiana, manufactures glass bottles and jars for the cosmetics industry. The total number of people employed by the two firms and their subsidiaries is slightly more than 100 . Together, they offor perfume and cosmetics companies a completely integrated package for their products. They are suppliers for many of the leading cosmetics firms in this country including Avon, Chesebrough Ponds, Coty, Estee Lauder and others. Their product line is very diversified and consists of hundreds of different sizes, shapes, and colors of injection molded caps.

Newburgh Molded Products has approximately 20 injection molding machines, some of which are capable of $1.8 \mathrm{MN}$ (400 thousand pounds) of force. These machines typically produce 10 to 12 caps per pressing in a molding process that takes only a few seconds for each batch. Two of these presses are completely automated except for the final packing of the products into shipping cartons. A particular run for a given cap may last about one week, but runs of several weeks are not unusual. Lot quantities may run into the hundred thousands. Typical cost per piece to the buyer is on the order of three to four cents each for a plain injection molded cap.

Many of the cosmetics firms desire caps for some of their product lines that look as if they have been gold, silver, or chrome plated. To do this in an inexpensive fashion requires a bit of old-fashioned Yankee ingenuity. To fill orders such as these, Newburgh Molded Products was sending the plastic bottle caps to I. V. Miller, a firm in Asbury Park, New Jersey, that specialized in metallic coatings of

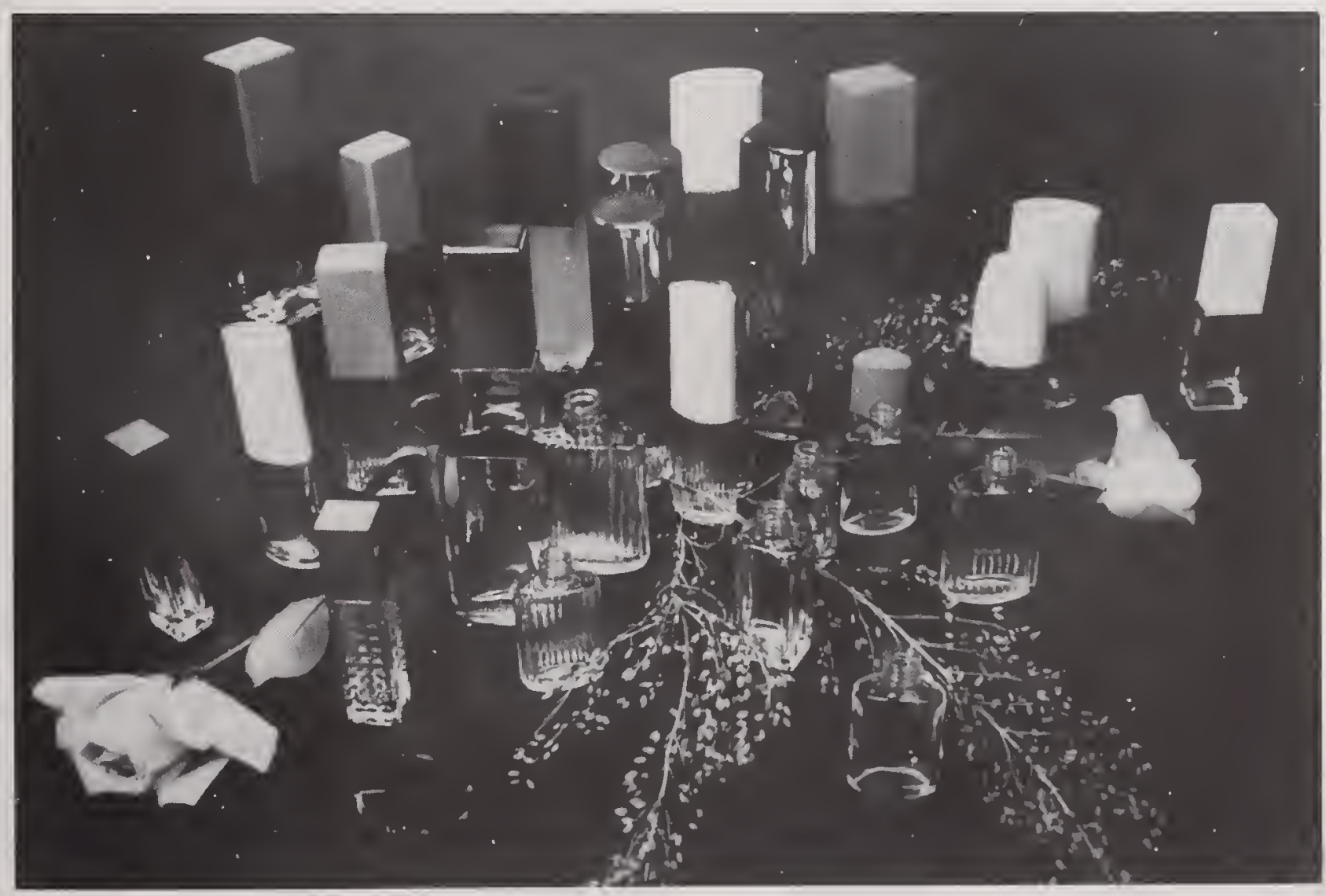

Figure 3. A wide variety of the special metalized plastic bottle caps commonly used in the cosmetics industry. 
plastic parts. In the first quarter of 1990, I. V. Miller decided to get out of this line of business which left Newburgh Molded Products without the capability to provide metallic-coated plastic caps to cosmetic firm customers. Newburgh Molded Products was offered the chance to purchase the vacuum metalization operation from I. V. Miller but no one at NMP had any expertise in the plating process.

At this point, the management at NMP had to make a number of tough business decisions as to whether it would be feasible to purchase the vacuum metalization operation, try to find a new plating firm, or develop a totally new facility in their plant in Newburgh, New York, which would incorporate newer, more modern processes in the manufacturing of these plated caps.

After extended considerations, Peter Polhamus, President of Newburgh Molded Products, decided to purchase the metalizing operation and move it to a new facility in Highland, New York, not far from the Newburgh facility. The new business venture was given the name of Newburgh Metalizing Corporation. Bill Laurent, the plant manager from I. V. Miller, was hired to manage the new facility in New York.

Peter Polhamus also decided to contact the Northeast Manufacturing Technology Center (NEMTC), headquartered on the campus of Rensselaer Polytechnic Institute in Troy, New York, to see if the center could provide some assistance with the implementation of the relocation-modernization of the plating process. Peter had learned of NEMTC's mission through their flyers and the New York State Extension Program. The staff at NEMTC suggested that Peter participate in the Center for Manufacturing Productivity and Technology Transfer's Manufacturing Internship Program. Under this program Peter could write a proposal to CMPTT (or NEMTC) to have an engineering student work with Newburgh Metalizing Corporation to assist with the engineering aspects of relocating the plating process from Asbury Park, New Jersey, to Highland, New York. The program provided that NEMTC and the private company cost-share the support for the engineering student on a 50/50 basis as he works on the project. The total cost to Newburgh Metalizing for this type of interaction was $\sim \$ 12,000$.

Senior engineering student Chris Kegan undertook this project. Chris spent some time in New Jersey studying the metalization operation and found that production rates needed to be improved as well as the quality of the product. Vacuum metalization of the plastic caps is a multistep operation consisting of spraying the caps with a base coat of an adhesive lacquer, then heating the base coat to cure it. This is followed by a vacuum metal- ization step in which the caps are coated with a thin layer of aluminum by flash evaporation in a vacuum chamber. At this point, the caps are ready for the final spraying operation which could be a clear coat in which the caps take on the look of being silver or chrome plated, or they could be sprayed with any one of a variety of colors of overcoat. Thus, for instance, they could be sprayed with a gold colored top coat which would give caps the appearance of being gold plated. The final step in the process involves curing this top coat, which in the existing process involves another slow, energyconsuming, oven-drying step.

The existing operation in New Jersey had topped out at 30,000 pieces per day. The cost to the cosmetics industry is only eight cents per cap, so the importance of mass production is quite obvious. Chris pinpointed the major bottleneck in the existing operation as the oven-drying of the spray coatings. The long time required and high cost associated with this step needed to be improved. A second area that needed improvement was the overall quality of the finished product. It was found that the major problem was with dust particles that wound up sticking to the undried spray coated caps. Chris found that a number of improvements could be made in the overall process, each of which would either lower production costs and/or improve the product quality.

In order to eliminate the batch oven-drying bottleneck, Chris suggested that a new state-of-the-art ultraviolet (UV) lamp curing system be purchased and integrated into the assembly line process. The UV equipment incorporates a new style of lamps that are a major improvement over conventional arc lamps. The new lamps last five times longer and reduce the amount of heat transferred to the part. The cure rate can be decreased to several seconds exposure with a conveyer rate of 12 meters (40 feet) per minute. Incorporation of the UV curing process reduces the cycle time for the production from 3.63 hours per cap for the thermal curing method to 1.35 hours per cap for the UV process. This translates into the production of an extra 20,000 caps per day, an increase of $66 \%$ over the thermal curing method.

Several improvements were made in the overall process which led to greatly improved overall product quality. The dust problem has been minimized by the installation of a $170 \mathrm{~m}^{3} / \mathrm{min}\left(6000 \mathrm{ft}^{3} /\right.$ $\mathrm{min}$ ) air replacement system in the entire facility which provides an over-pressure environment. A 73 $\mathrm{cm}$ (two foot) diameter tube is located overhead which extends the length of the production facility. It has holes located along the length of the tube which provide an even distribution of fresh air from the outside. Bringing in fresh air from the outside from the top of the building forces the flow 


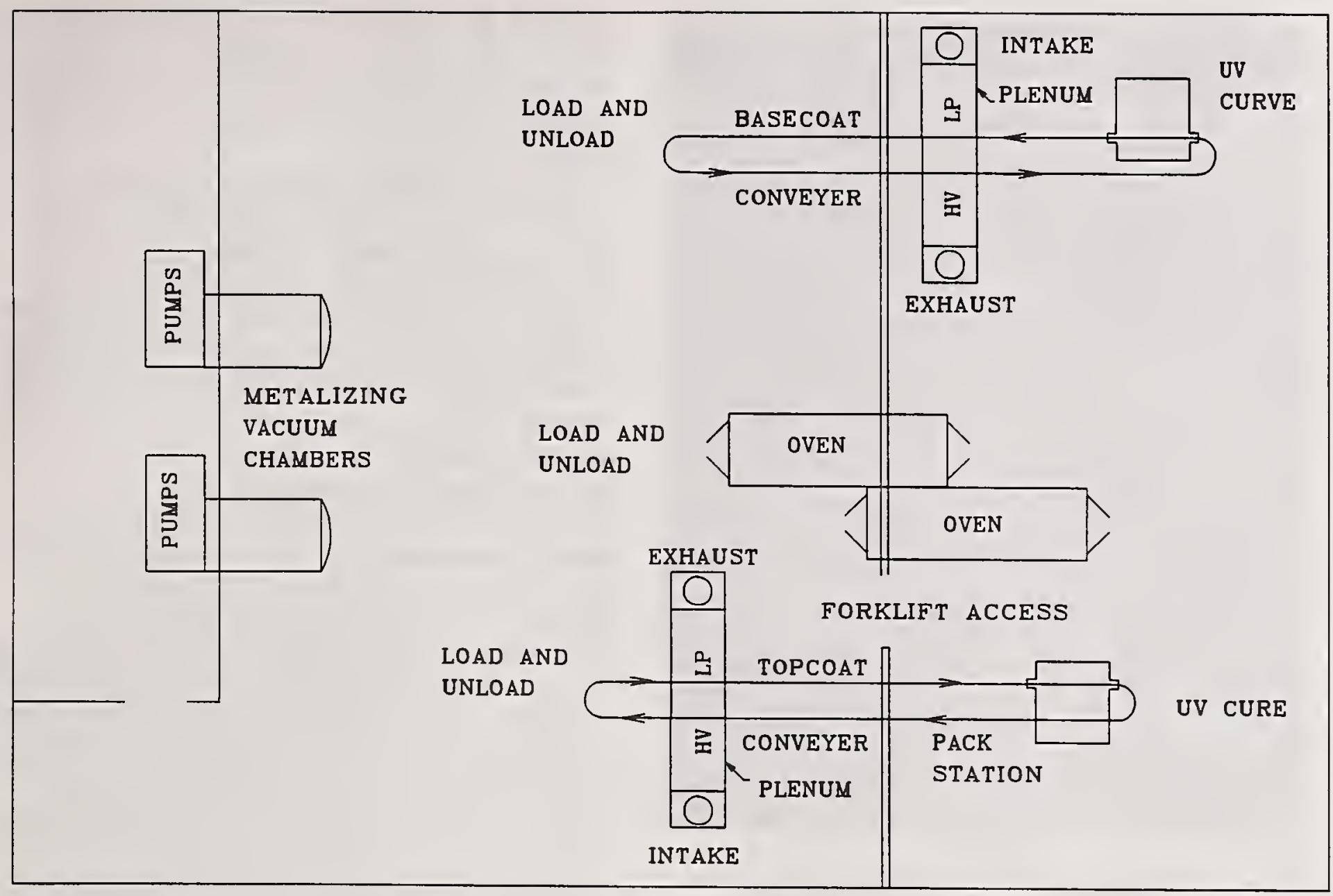

Figure 4. Plant layout of the metalizing plant in Newburgh, New York, showing the implementation of the new on-line UV curing for the metalized bottle caps.

out of the building down to floor level, thus eliminating the major portion of the dust and fumes in the building. This has greatly increased the product quality by eliminating imperfections in the metalized caps caused by dust particles sticking to the freshly sprayed surfaces. In addition, air conditioning and humidity controls were installed to further facilitate faster curing and drying of the sprayed parts.

Another major improvement was obtained by converting to a new type of high-volume, lowpressure (HVLP), automatic paint spraying system. In the production process at the I. V. Miller company, conventional high-pressure paint spraying equipment was employed for spraying the lacquer basecoat and topcoat. These paint guns were powered by $22.4 \mathrm{~kW}$ ( 30 horsepower) air compressors. The lacquer was sprayed at $400 \mathrm{kPa}\left(60 \mathrm{lb} / \mathrm{in}^{2}\right)$ with about $20 \%$ efficiency. The HVLP spray system chosen by Newburgh Metalizing is manufactured by AccuSpray Company of Cleveland, Ohio. Coincidentally, this spray system was developed with the assistance of the Great Lakes Manufacturing Technology Center. (See the accompanying case history in this book.) In general HVLP paint spraying systems are $65 \%$ to $90 \%$ efficient compared with a 20 to $25 \%$ efficiency for a conventional high-pressure spray system. Furthermore, since it is a low- pressure system, a turbine can be used to provide the air pressure. This eliminates the problem of oil and water contamination, commonly found in compressed air lines, which can ruin the finish. Incorporation of an HVLP spray system cuts down on the amount of lacquer needed to coat the caps which results in enormous savings. Typical payback time on one of these systems is on the order of one month due to the savings of paint costs alone.

A final addition to the operation was the development of a Lotus spreadsheet which contains information on production, costs, and pricing. The parameters in this data base can be used to estimate overall costs of the final products on a perpiece basis. Various scenarios can then be tried to see how the parameters chosen affect the cost of the final product.

\section{Brimfield Precision Inc., Brimfield, MA}

Brimfield Precision is a small manufacturing firm that specializes in the manufacture of class III (implantable) prosthetic body parts such as replacement hip joints and knee implants. The firm is located in Brimfield Massachusetts, a small town approximately 50 miles southwest of the Boston metropolitan area. The firm is housed in a modern $1800 \mathrm{~m}^{2}\left(20,000 \mathrm{ft}^{2}\right)$ facility located in a rustic 


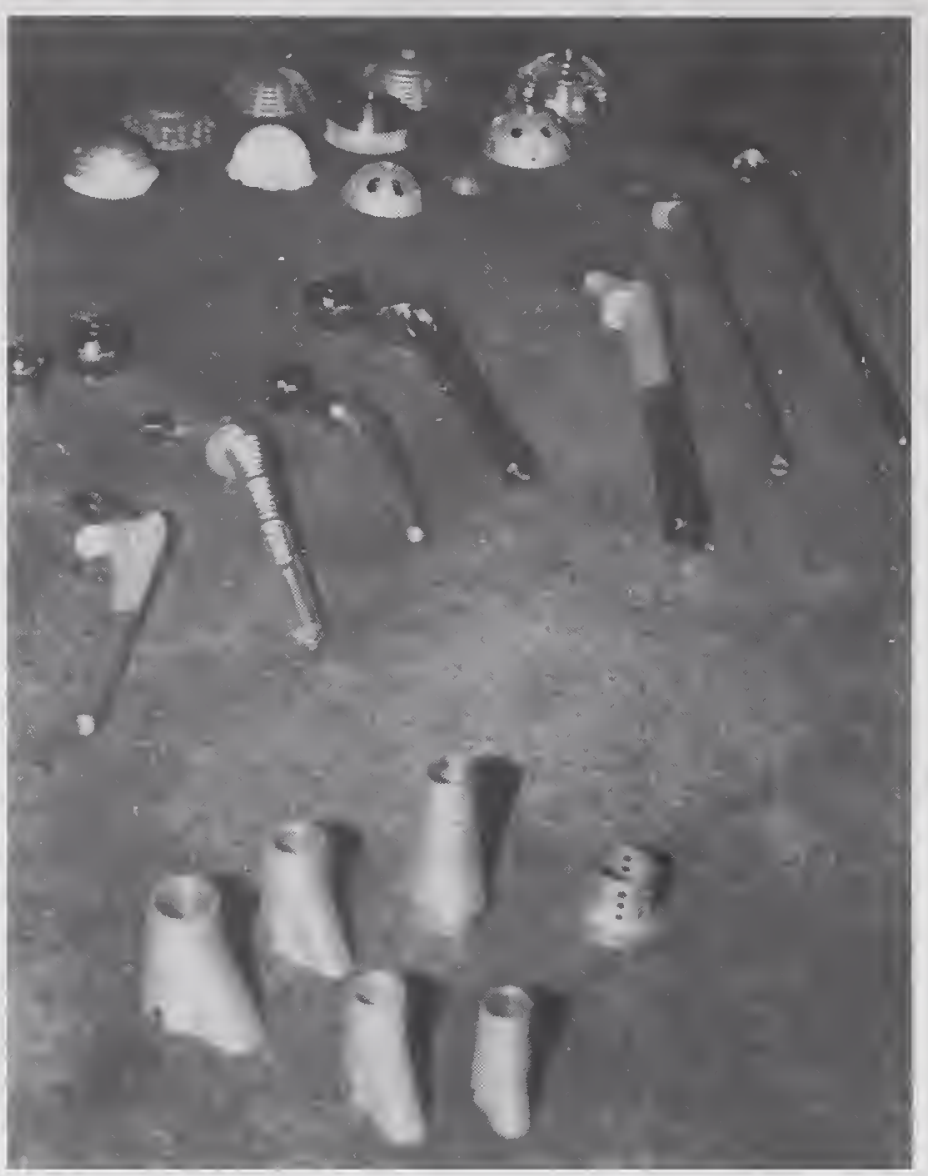

Figure 5. A variety of the complex-shaped titanium orthopedic replacement joints that are manufactured by Brimfield Precision.

New England setting. They have been in business since 1967 and currently have 86 employees. In the past few years the firm has been in a strong growth mode with a target of $25 \%$ growth per year.

In addition to the implantable prosthetic body parts, the firm also manufactures a number of the surgical instruments that are used in the operations associated with implantation of these devices as well as arthroscopic instruments used in many state-of-the-art surgical procedures. As one might envision, in this manufacturing environment the devices to be produced require a number of complex machining steps, all of which must be done with great precision. Furthermore, many of the implant devices are made out of titanium, an extremely difficult material to machine. Most of the surgical instruments are made from stainless steel which is also a hard-to-machine material. Lot sizes for the various implants and surgical instruments range from nearly one-of-a-kind to batches of 10,000 .

The nature of their manufacturing process requires some rather sophisticated machining equipment. In order to be at the leading edge of their field, Brimfield precision has developed a strong Computer-Aided Manufacturing (CAM) program for all of their machines.

All this has led to the need to improve the firm's Computer-Aided Design (CAD) operations and to integrate the CAD with the CAM so that the end result is one in which the machine tool path can be computer generated directly from the CAD drawing without going through additional manual conversion routines.

In order to upgrade their CAD facilities, Bill Lyons, President of Brimfield Precision, and his staff of engineers began evaluating some of the CAD packages available in the software market. After looking at 15 to 20 different systems, they were leaning toward the purchase of a large mainframe computer with a number of attached workstations. The price for a system of this type was close to $\$ 250,000$. For a small firm like Brimfield Precision, this was a difficult decision to make since it needed to be absolutely certain that the system chosen would fulfill all of the company's needs for the next few years. Bill Lyons had learned of the NIST-sponsored Manufacturing Technology Program through the Technologies for Effective Cooperation Network (TECnet) Program. This program is a satellite operation of the Northeast Manufacturing Technology Center (NEMTC) which operates out of Tufts University. Bill arranged to visit the Manufacturing Technology Resource Facility (MTRF) on the campus of Rensselaer Polytechnic Institute in Troy, New York. The MTRF is operated by NEMTC which is also headquartered at RPI. While there, he talked with Jerry Crucetti, head field engineer for NEMTC, and Rick Korchak who is in charge of the MTRF. The MTRF has over 50 software packages on line and a variety of hardware configurations ranging from PCs to workstation environments. Rick Korchak and his staff are available to assist people like Bill Lyons and his engineering staff in order to help them make intelligent decisions as to the best combination of hardware and software for their particular CAD/CAM application. Rick arranged for Bill Lyons and his engineering staff to attend a one-day CAD-awareness course at the MTRF. Following this course Bill and his engineering staff spent several days at the MTRF obtaining hands-on experience with a number of CAD programs. Eventually they narrowed the field down to two or three systems that would be adequate to handle the workload at Brimfield Precision. In the end, two workstations were purchased which used Intel-386 microprocessor based PC technology. These two computers and the CAD software were purchased for approximately $\$ 30,000$ which resulted in saving Brimfield Precision approximately $\$ 220,000$ when compared with the large mainframe type of package they were originally considering.

As a result of the interactions with NEMTC, Brimfield Precision now has the ability to do all of its own CAD/CAM in-house design and development work. The company has also expanded its 
operations to include custom design and development work for other firms. It has the ability to receive IGES or DXF format CAD drawings from client firms electronically. Once the drawing is received and transferred to computer memory, it can be displayed on the computer screen in a matter of minutes. This greatly facilitates the design work that the company does for client firms.

Now that Brimfield has the enhanced computer capabilities, NEMTC is working with Bill Lyons to establish a computerized production control system for inventory management and computer tracking of manufactured parts.

\section{AccuSpray/Bessam-Aire, Bedford Heights, $\mathrm{OH}$}

AccuSpray and Bessam-Aire are sister companies that share common manufacturing facilities in Bedford Heights, Ohio, an eastern suburb of Cleveland. Bessam-Aire is owned by Joe Marg and AccuSpray is owned by his son Ken. AccuSpray has 33 employees and specializes in high-volume, lowpressure (HVLP), paint spraying equipment. This system of paint spraying is relatively new to the market but definitely the way of the future.

Bessam-Aire has 40 employees. The firm manufactures general air handling equipment which is used in factory environments which require large exhaust systems in combination with replacement make-up air ducts. Bessam-Aire has been in business for 30 years while AccuSpray is relatively newer, being founded in 1981. Together they have yearly sales in excess of $\$ 18$ million. These two companies have had several interactions with the Great Lakes Manufacturing Technology Center (GLMTC) involving plant reorganization, installation of business computer systems for each company, a CAD expansion project, and a redesign of some key products in the AccuSpray product line.

After several visits to the AccuSpray/BessamAire manufacturing facility and numerous talks with the management and engineering staff, $\mathrm{Hal}$ Feightner and the staff at the GLMTC prepared four studies and presented the results to Joe and Ken Marg. The total cost for these studies to Bessam-Aire/AccuSpray was approximately $\$ 15,000$. As described below, the return on this investment has been manyfold.

Improving the manufacturing facilities began with the plant layout. As presently configured, the current plant layout was not efficient, with AccuSpray and Bessam-Aire staff and facilities being haphazardly strewn throughout the facility. The sprawling $5,500 \mathrm{~m}^{2}\left(60,000 \mathrm{ft}^{2}\right)$ building that houses the two companies is rectangular in shape with a dividing wall down the length of the building. All the shipping was done out of one side of the building which presented a serious materials flow problem. Hal suggested that the first thing on the agenda should be the reorganization of the entire facility. AccuSpray was relocated to occupy $1800 \mathrm{~m}^{2}$ $\left(20,000 \mathrm{ft}^{2}\right)$ of space, principally on one side of the building, and Bessam-Aire the other. A large opening was cut in the middle of the large central dividing wall to allow forklift access to both sides of the building. The AccuSpray operation was laid out so that it now has its own shipping doors on the opposite side of the building from Bessam-Aire. AccuSpray's Ken Marg relied heavily on his own staff to implement the relocation of AccuSpray's facilities. After the relocation was completed, the staff was organized into three six-person teams which has streamlined the production process. One team now handles only the shipping aspects of the operation, and the other two assemble the spray guns and compressor systems. Each team essentially has its own workcell environment, and parts are within easy reach of the personnel who are doing the assembly operations. This team-assembly concept along with the improved plant layout has greatly improved the overall operation. Prior to implementation of the GLMTC plan, the production cycle, setup-assembly-shipping, took three weeks. It now takes two to three days. Ken Marg is currently fine tuning the process by converting to a continuous assembly scheme which would time output to match the incoming order flow. He hopes that this would cut the total time to a one-day turnaround. All of the improvements have increased the profit margin from $25 \%$ to $45 \%$ on the new spray guns.

Bessam-Aire's heat exchanger production facilities were organized into three assembly lines, similar to those used on automobile production lines. Previously, various aspects of the production had been scattered throughout the building. The machine shop was moved to a more convenient location and reorganized to take up less space.

The results of this reorganization enabled AccuSpray to avoid building a new plant which saved the company an estimated $\$ 500,000$. The plant reorganization required little capital investment, but resulted in important productivity increases for both AccuSpray and Bessam-Aire. Material flow was improved and in-plant travel and shipment backlogs were reduced. The plant reorganization enabled AccuSpray to keep up with increased demand and maintain quality during a critical period of growth.

While the AccuSpray facilities were being relocated, the GLMTC staff began work with the Bessam-Aire side of the company which resulted in the Bessam-Aire production facilities being greatly 
improved. Bessam-Aire's product line is the design and construction of large air-handling sheet metal ductwork for factory installations that require large amounts of air to be exhausted from the workplace environment. In a typical installation, many "standard" components are used, but of course each installation is also somewhat of a custom job which requires a new design of components and special placement of vents and air intakes in locations that are specific to the job at hand. Before the assessment by the GLMTC staff, all drawings were done by hand on an individual basis which sometimes required several weeks to complete. GMLTC's Feightner suggested that the staff involved with preparing the drawings for the custom-made Bessam-Aire products consider using ComputerAided Design (CAD) for preparing the drawings to be mailed out to potential customers. Key potential users were queried and all requirements combined to establish the key elements needed in a software system. The staff at GLMTC then reviewed a number of software packages and assisted the staff at Bessam-Aire in the selection process. Now drawings for new installations can be facilitated in a matter of several days using an array of more-orless standard sub-drawings which can be pieced together quickly to form a final working drawing. This allows Bessam-Aire to respond quickly to companies requesting installation of air handling systems. In addition, changes and modifications are quickly and easily made with minimal effort. It is estimated that for each workstation in operation, Bessam-Aire will save $\$ 40,000$ per year. BessamAire currently has three workstations in operation and a fourth is being considered.
The low-pressure paint spraying market is growing rapidly due, in part, to some stringent environmental legislation which has recently become effective in California, Texas, and New York which bans the use of spray guns that can not put at least $65 \%$ of the paint on the target. Similar laws are pending in 28 other states. High-pressure paint spraying is a very inefficient process which uses a good deal of solvent and is at best only $20-30 \%$ efficient in the transfer of paint to the target. In a typical high-pressure system, compressed air at $200-500 \mathrm{kPa}\left(30-80 \mathrm{lb} / \mathrm{in}^{2}\right)$ is used to drive the paint and solvent from the spray gun to the target. So in addition to being inefficient, a source of compressed air, either from a tank of air or bulky compressor itself, is necessary. The high-volume, low-pressure spraying method on the other hand operates using a different principal. Typically 13-66 $\mathrm{kPa}\left(2-10 \mathrm{lb} / \mathrm{in}^{2}\right)$ is all that is needed to operate the system. At these low pressures, a lightweight centrifugal compressor can be used to generate the pressure differential. The process of putting paint on the target is much more efficient, typically 65$90 \%$.

AccuSpray has been a leader in this field for a number of years, but it is not resting on its laurels. The firm is always striving for improvement in the product line. In addition to constant tweaking of the gun and nozzle assembly which is done inhouse by the AccuSpray engineering staff, Ken Marg felt that the compressor that was being used in all of AccuSpray's line of paint spraying systems could stand some improvements. AccuSpray's lowpressure equipment currently utilizes a centrifugal compressor which satisfies all environmental

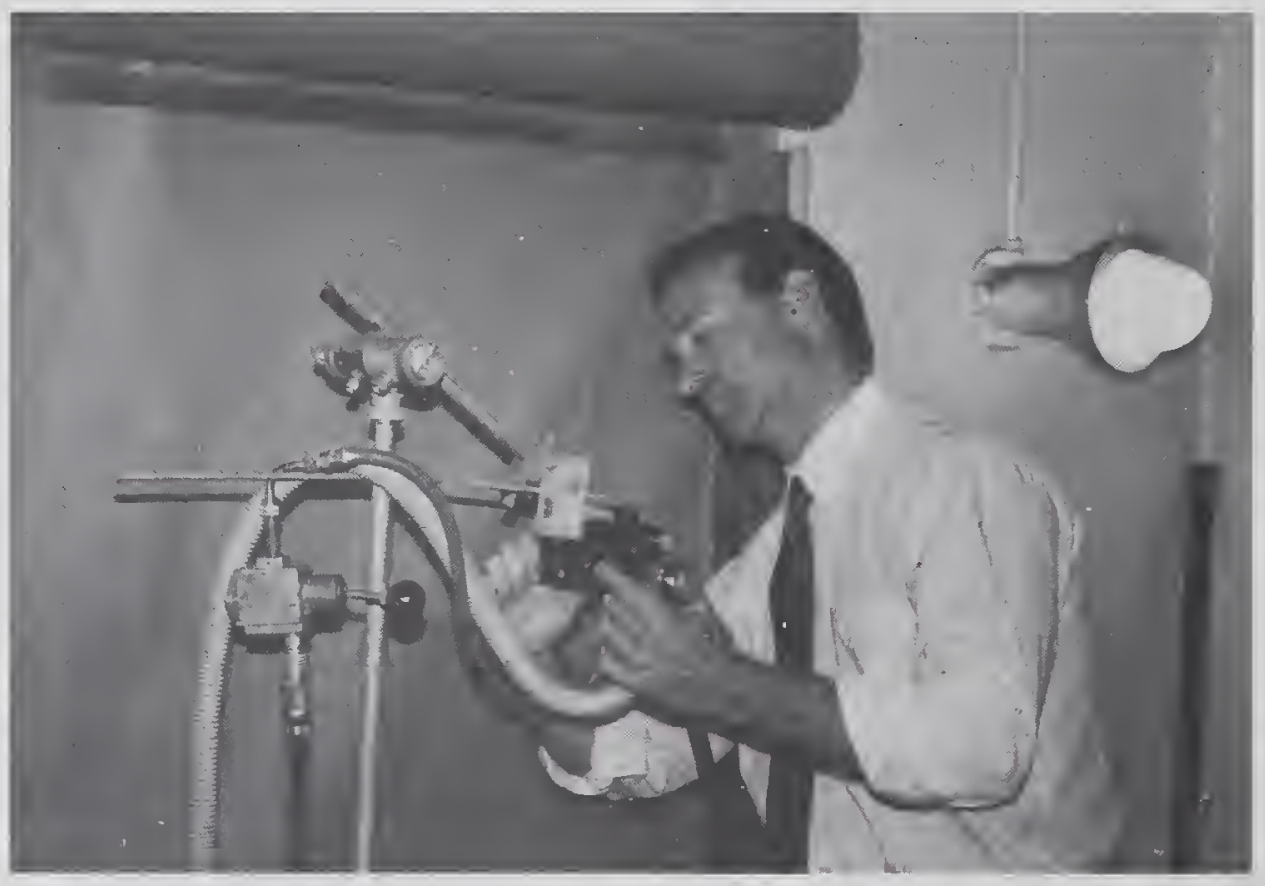

Figure 6. AccuSpray's Chief Engineer, Bob Amicarelli, preparing to shoot a test spray pattern with one of AccuSpray's new HVLP spray guns that are designed for continuous-duty spray applications. 
restrictions; however, it suffers from some drawbacks in that it needs servicing regularly. Ken felt that a number of improvements could be made in the design but needed engineering assistance in bringing his ideas to fruition. Since he had already had previous interactions with the GLMTC, he approached the staff at GLMTC for assistance with the engineering aspects of this problem. GLMTC called in several members of the engineering staff from Cleveland State University to discuss the redesign of the centrifugal compressor used in the paint spraying operation. The engineering staff essentially started from scratch and designed a completely new compressor. The new compressor operates at lower speed (3,600 rpm vs. $12,000 \mathrm{rpm})$ which allows it to be run in a direct drive fashion from a more standard electric motor rather than a geared design or a high-speed electric motor. The new design is less expensive to maintain and lasts much longer than the original model. It generates less heat (exhaust gas at the paint gun is $88^{\circ} \mathrm{C}$ vs. $149^{\circ} \mathrm{C}\left(190^{\circ} \mathrm{F}\right.$ vs. $\left.300^{\circ} \mathrm{F}\right)$ for the old compressor) and as a result is $50 \%$ more efficient than the original model.

In order to attain these improvements, more efficient rotor blades were designed using airflow and aerodynamic modeling equations. The number of compressor stages were optimized, and the compressor's rotational axis was changed from a vertical to a horizontal design. In addition, oil-fed journal bearings similar to those employed in engine crankshafts were employed in lieu of ball bearings at the ends of the shaft. The shaft design was modified by removing more metal. Finally a low-cost housing was designed to replace the highpriced casting used in the old unit. Presently, AccuSpray has not yet implemented this new compressor design but is exploring the possibilities of having the engineering staff at CAMP design a series of new compressors for the various different models of AccuSpray's paint systems. This would allow each system to employ the optimum compressor. For instance, in the low-priced end of AccuSpray's product line which taps the home owner or nonprofessional market, a unit designed with less costly ball bearings instead of oil-fed journal bearings would be adequate.

AccuSpray expects to have sales of over $\$ 11$ million in 1991 which is a $57 \%$ increase over 1990.

The firm predicts an increase in sales $2-3$ fold over the course of the next two years, and the numbers could be even greater if other states follow California, Texas, and New York in enacting stricter environmental legislation. It is interesting that AccuSpray is faced with a marketing paradox in that many of its distributors also sell paint and thus would rather sell less-efficient, high-pressure, paint spray systems so they can sell more paint. The dis- tributors realize that every time they sell an AccuSpray gun to a customer, they will be selling half as much paint to that same customer.

\section{Masco Machine Inc., Cleveland, $\mathrm{OH}$}

\section{Masco Machine Inc. designs and builds com-} pletely automated machining centers which are used in automotive, truck, tractor, and heavy machinery production line facilities producing engine blocks, crank- and camshafts, transmissions, and a wide variety of similar machined steel components. It is a privately held company in business since 1962 , located in Cleveland, Ohio, with an annual sales of $\$ 15$ million. The company has $85 \mathrm{em}$ ployees and is housed in a modern $6,500 \mathrm{~m}^{2}(70,000$ $\mathrm{ft}^{2}$ ) facility. It manufactures a standard line of automated $\mathrm{CNC}$ single- and multi-spindle machining centers as well as custom-built machining centers to user specifications. (Its largest machine was de-

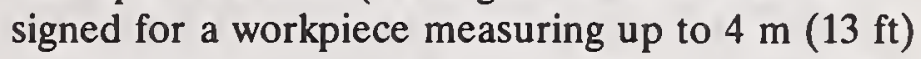

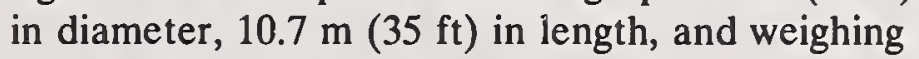
$9,000 \mathrm{~kg}(20,000 \mathrm{lb})$.

Masco has had two interactions with the Great Lakes Manufacturing Technology Center (GLMTC). In 1989 Masco wanted to upgrade its computer facilities in order to streamline its operations. Masco was at the leading edge of its trade, but its computer facilities were near saturation. Two separate areas were addressed in the study carried out by staff of the GLMTC. The first area is the office systems division and the second area is the design and engineering laboratory.

For the office system environment, Masco was using a series of Apple Macintosh computers, two PC-AT computers, and an older system that was not directly compatible with either Apple or PC systems. The engineering lab also used several PC-AT computers. Coordination between these systems was manual; i.e., they were not connected via a local area network (LAN). Bob Eckert and Gary Conkol of GLMTC worked with Steve Fedor of Masco to develop a comprehensive plan to improve office systems computational power. After reviewing the computer environment at Masco the GMLTC staff made a number of suggestions. First, Masco needed to upgrade its current computers to make them state-of-the-art, and GMLTC recommended several new additional computers be added. The next logical step would be to add a minicomputer to act as a multitasking file server. Following this, a LAN system should be installed to connect all the current Apple computers, PC-AT computers, and several new workstations together. In addition, the LAN should also link the design and engineering laboratory to the office systems. The GLMTC staff suggested that Masco contact 
several major vendors and let the vendors propose a block diagram of the expansion as they would recommend it. GLMTC would then assist Masco in evaluating the vendors' proposed equipment and software systems.

As a result of these studies, Masco has begun implementation of a number of the recommendations. The office system group and the engineering laboratory have both acquired additional computers, and others have been upgraded. The networking question is still being addressed, but it is the next step in the computer systems upgrade.

The second interaction that GLMTC has with Masco is still evolving. It involves proof-of-process metrology on a transmission component manufactured by Ford Motor Company. Masco utilizes a technique known as "microfinishing" or "superfinishing" which uses abrasive belts to finish even the hardest steel parts to a mirror finish. Typically, aluminum oxide or silicon carbide belts are used in this process. Finishes as smooth as $\approx 1 \mu \mathrm{m}$ ( $30 \mathrm{mi}$ croinches to 10 microinches) can be obtained. This unique finishing process frees the surface metal from fragmented and smeared metal particles produced in previous machining operations. In addition, the surface integrity is restored by eliminating surface burns and stresses. In the current engineering project with Ford Motor Company, Masco is to develop the equipment and techniques necessary to produce a transmission part in the Ford Motor Company production line. In the existing process, the part is rough-turned, ground, and then rollerburnished to the necessary size and finish.
In the new process being proposed by Masco, the part goes directly to the microfinishing process after being turned, thus eliminating the grinding and burnishing steps while increasing the quality of the finished part. The assistance to be provided by GLMTC involves process metrology of the machined parts using an optical comparator, critical evaluation of the measurements to be made, and documentation of the results. Edward Cambron of the CAMP affiliated Unified Technology Center's (UTC's) quality group and Michael Kolbe and Jack Wright of the GLMTC staff are in charge of performing the measurements using state-of-the-art metrology equipment available at the UTC. Steve Fedor of Masco is assisting in obtaining these measurements in order to obtain a better understanding of the equipment features and capability in the MRF. An optical comparator was chosen for these measurements over conventional instruments, since it is equipped with glass scales, an electronic edge detector, and a calculating digital readout. On relatively smooth surfaces, dimensional readings within $\pm 2.54 \mu \mathrm{m}( \pm 0.0001$ inch) repeatability can be obtained. Rough surfaces provide more of a challenge because care must be taken in order to avoid hitting "peaks and valleys" of the tool marks. Another advantage of using the optical comparator for these measurements was the ability to observe form variations which can be indicative of certain process variables. For instance, when one of the first units produced was tested, it was noticed that tapers of several ten thousandths were present on the ends of a cylindrical area, which produced a slight

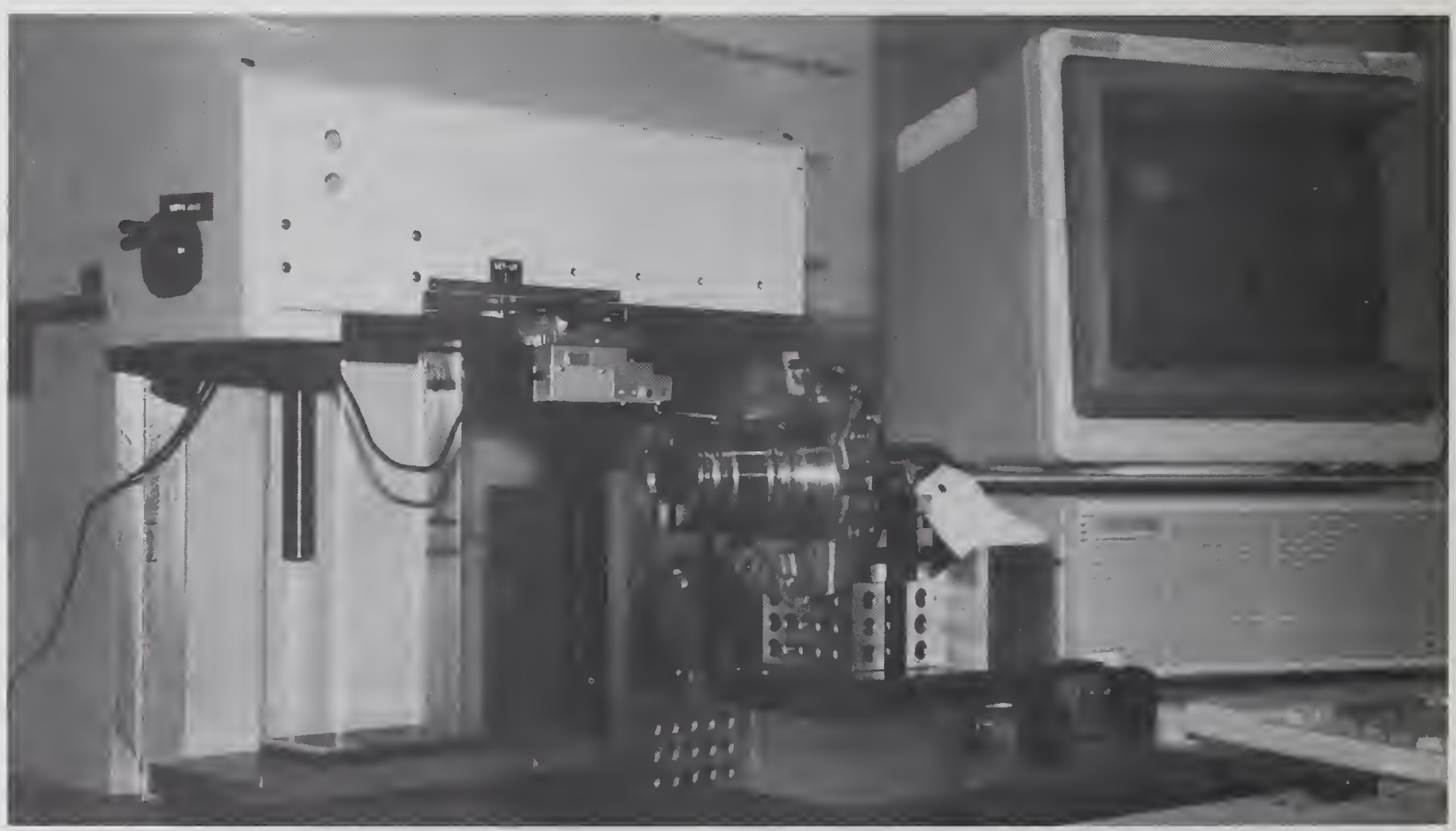

Figure 7. A transmission part being tested on the optical comparator at the GLMTC's Manufacturing Resource Center. 
barrel-shaped distortion in the part. Steve Fedor of Masco noted that this could be caused by excessive pressure on the part during axis reversals of the machine and said that he could adjust the machine to eliminate this.

In the initial phase of the work, a total of 12 parts are to be measured, both before and after the microfinishing process. The cost to Masco for the project was $\$ 600$. With a conservative estimate of savings of $\$ 0.20$ per part produced and Ford Motor Company's estimated production of 12,400 parts per week, the new process would mean an annual savings of over $\$ 125,000$ for Ford. Furthermore, it is anticipated that the proposed process would produce a superior part to the one currently in use. While such advantages are difficult to quantify, they would likely produce additional savings in terms of overall product performance and decreased warranty repairs.

For Masco, a small company, successful completion of this project may also open up considerable new sales potential for several more systems in following years. It is estimated that Masco could realize an increase of $\$ 600,000$ in sales by demonstration of proof-of-process with the Ford Motor Company part.

\section{STERIS Corporation, Mentor, $\mathrm{OH}$}

STERIS Corporation is a manufacturer of sterilizing systems for surgical instruments. It is a privately held firm that began operations five years ago. The business is headquartered in Mentor, Ohio, a suburb of Cleveland. Currently STERIS has 94 employees and is in the midst of rapid growth, with projected sales of $\$ 50$ million in 1995. Until recently, it sold only on the domestic market, but this year it has expanded into the European market.

STERIS manufactures and markets a unique liquid chemical sterilization system for surgical instruments that utilizes an oxidative chemical solution of $30 \%$ peroxyacetic acid $\left(\mathrm{CH}_{3} \mathrm{COOOH}\right)$ that contains a proprietary mixture of corrosion inhibitors and buffers that maintain a neutral $\mathrm{pH}$. The solution used in the sterilizer is effective at $50^{\circ} \mathrm{C}\left(122^{\circ} \mathrm{F}\right)$ in 12 minutes of contact. The STERIS PROCESS ${ }^{\mathrm{TM}}$ is more effective than glutaraldehyde at reaching contaminated surfaces and does not present the hazards associated with glutaraldehyde, ozone, steam, or ethylene oxide. The STERIS PROCESS ${ }^{\mathrm{TM}}$ was born from the need for a low-temperature sterilization system that would rapidly sterilize delicate surgical, dental, and diagnostic instruments without harming the plastics and other composite materials that were used in constructing the instruments. Candidates for the STERIS PROCESS ${ }^{\mathrm{M}}$ are any immersible medical instruments, such as microsurgery instrument sets, flexible endoscopes and forceps, rigid endoscopes, and video cameras that are often used in minimally invasive surgical and diagnostic procedures.

The STERIS SYSTEM $1^{\mathrm{TM}}$ sterilization unit was designed to accommodate a variety of different instrument trays. The most common tray simply utilizes a rectangular configuration in which general surgical instruments can be placed for sterilization. Three other tray designs are currently offered with the sterilization unit which are designed specifically for a given instrument with a complex shape, such as an endoscope. The tray design is optimized to attain a maximum flow of sterilizing solution around the instrument(s) being sterilized. The instrument trays are offered as additional accessories so that only the required trays need be purchased by any given customer.

A major difficulty encountered by Norman Siegel and his product development group at STERIS focuses on the design and construction of new instrument trays for the instruments. The majority of these require extremely complex shapes. Since STERIS SYSTEM $1^{\mathrm{TM}}$ was designed to be a turnkey, user-friendly system that anyone could use, a major tray design constraint centers around the standard chemical charge that is used in the sterilizing system. The chemical charge comes prepackaged and is designed for a 10 liter working volume. STERIS was spending an inordinate amount of

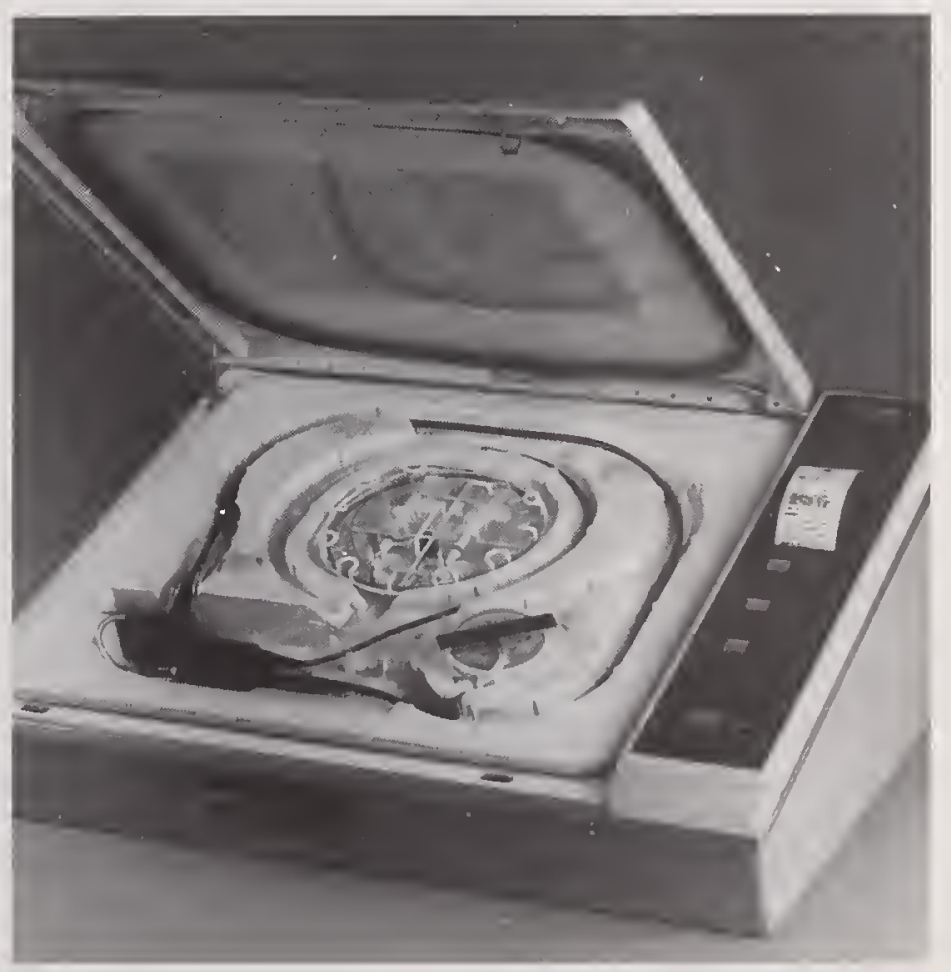

Figure 8. STERIS SYSTEM $1^{\mathrm{TM}}$ sterilization unit showing the complex shape of the instrument tray necessary for sterilization of an endoscope. 
time and effort on new tray design. In order to design a new tray, a working prototype mold had to be constructed. Depending on the complexity of the tray, this working prototype could cost as much as $\$ 20,000$. Following this, test trays were thermoformed and trial runs made in the sterilization system. Design errors of only $3 \mathrm{~mm}$ (1/8 inch) in some parts of the trays lead to volume errors of 0.5 liters. If the volume was too large (i.e., >10 liters), the working prototype had to be remachined at a cost of several thousand dollars, following which the whole prototyping sequence had to be reinitiated. Many techniques were tried in order to minimize the trial-and-error nature of the design process, but none were found to work well. Norman Siegel had grown up with computers and was well versed in their use. He realized that the best way to design trays would be to use some sort of CAD/CAE package, but he also knew that there are literally hundreds of software CAD packages on the market. At this point he contacted the GLMTC for assistance on the selection of the best software package for STERIS' application. Gary Conkol, the GLMTC's Technical Program Manager, and David Thomas-Greaves, Manager, Technology Application Engineering of the GLMTC, assisted STERIS in the selection of an appropriate CAD system for use in optimizing tray designs. As is typical for all of the Manufacturing Technology Centers, the staff in charge of the demonstration facility is thoroughly familiar with all the latest software packages and state-of-the-art hardware. Demonstrations and tests of three major software packages and four different hardware platforms were conducted and quotes obtained. GLMTC charged STERIS $\$ 1200$ for this service. It was found that a system meeting STERIS Corporation needs would cost between $\$ 45,000$ and $\$ 60,000$ for one workstation. The potential for STERIS, however, was estimated to be over $\$ 110,000 / y r$ in labor savings alone based on eight hours a day utilization. Additional benefits derived from faster time to market (up to 65\%, better initial design resulting in fewer prototypes, and application to new products were not quantified. The specific recommendation was to purchase a CAD system for tray design and apply it to complete assembly design as internal expertise increases. A second workstation should also be considered for backup, training, and modelling support.

STERIS currently has purchased one CAD/CAE workstation and is using it to design additional instrument trays for the sterilization system. It has helped immensely to cut down on design costs for these trays and makes it much easier for STERIS to initiate designs for new instruments as they are developed for the medical industry. STERIS is now purchasing additional equipment to expand their CAD/CAE capabilities.

\section{Roller Bearing Company of America, Hartsville, SC}

Roller Bearing Company of America (RBC) is a major supplier of bearings to a wide range of end users, including farm equipment, marine power, aircraft, and construction equipment industries. The firm is headquartered in Hartsville, South Carolina, a small town of 8000 people, located in the middle of a rich agricultural region of South Carolina's delta. RBC has been in business since the early 1900s and moved to South Carolina in 1964. Since 1964 its manufacturing facilities have grown from $2,800 \mathrm{~m}^{2}\left(30,000 \mathrm{ft}^{2}\right)$ to more than $7,900 \mathrm{~m}^{2}$ $\left(85,000 \mathrm{ft}^{2}\right)$. The company currently has $174 \mathrm{em}-$ ployees. Its product line consists of spherical plain radial bearings; precision-ground, heavy-duty, needle roller bearings; and cam followers. RBC's needle bearing line encompasses a variety of sizes from those with a small $0.635 \mathrm{~cm}(0.2500$ inch $)$ bore to those with a rather massive $58 \mathrm{~cm}(23.000$ inch) outside diameter.

The manufacturing of roller bearings is a field where the technology employed has been in use for some time. Many of the machines now in use were designed and developed well before the advent of the CAD/CAM revolution of the last decade. In situations such as this it is easy for management to take the status quo approach and not want to make changes in a time-proven system. The progressivethinking management at RBC, headed by Charles Holmes, however, realized that to remain competitive in the 1990s improvements would have to be made in many of the techniques currently employed in the roller bearing manufacturing process.

In September 1990, Charles Holmes attended one of the CEO breakfast meetings sponsored by the Southeast Manufacturing Technology Center (SMTC). These meetings are held periodically throughout the state of South Carolina 40 as a way of introducing local firms to the facilities and services available to them through the SMTC. The meeting attended by Charles Holmes was held in Florence, South Carolina, a major city not far from RBC's Hartsville headquarters. At this breakfast meeting he met Curtis Rhodes of the SMTC. Following the meeting additional conversations were held which eventually led to several interactions between the SMTC and RBC. Charles realized that the technical specialists associated with the SMTC had expertise in a wide variety of areas, some of which could be applied directly to help in making improvements in the manufacturing environment at RBC.

Charles Holmes arranged for Curtis Rhodes, a technical specialist of the SMTC, to visit the Roller Bearing Plant in Hartsfield, SC. Following the site 
visit, Curtis had a number of suggestions for improving some of the manufacturing processes at RBC.

One of the areas where there was a mutual feeling that improvements could be made was in the heat treating process of the bearing materials. Following the rough machining of bearing parts, the parts next go through a heat treatment process where the hardness is raised to Rockwell $60-62^{\circ} \mathrm{C}$. This is a through-hardening process where the parts are heated to approximately $800^{\circ} \mathrm{C}\left(1500^{\circ} \mathrm{F}\right)$ followed by a quench.

The furnaces are batch type and either electrically or propane heated. Curtis Rhodes carried out an energy analysis with a goal to determine the feasibility of reducing energy costs. He performed an analysis to determine the efficiency of the furnaces as they were operated. Then the energy used for the heat treatment was determined by the amount of propane used in one month for heat treatment.

The minimum energy absorbed that would be required is determined by the heat capacity of the bearing material and the weight of bearing parts heat treated during the one-month period. The difference between the propane energy purchased and absorbed in the metal are the resultant losses. The losses primarily occur through the furnace doors and walls and from the gases released to the stack.

The furnace efficiency is the ratio of the energy absorbed by the metal to the fuel energy released during combustion. The study performed by Curtis indicated the losses were significant. As a result of this study RBC made a number of modifications both in its process stream and ovens themselves which resulted in a much-improved furnace efficiency.

The SMTC also assisted RBC corporation in a totally separate area from the heat treatment process described above. As one might expect, for an industrial process which produces high-precision parts, an area that RBC devotes a good deal of time to is that of metrology, and how best to certify that the bearings being produced meet the exacting standards required for this type of part. Typically tolerances of $\pm 10 \mu \mathrm{m}$ ( \pm 0.0004 inch) must be maintained in the construction of bearing races and tolerances of $\pm 2.54 \mu \mathrm{m}$ ( \pm 0.0001 inch) must be maintained in the rollers. In addition, surface finish, roundness, and hardness specifications must be met. Currently each piece is checked to ensure that the tolerances are within the required specifications. Curtis Rhodes suggested that Carol Whinham, a technical specialist of the SMTC, be called in to assist RBC in improving the metrology operations. Carol has had extensive experience in the area of statistics. After a thorough review of manufacturing operations at RBC, Carol suggested that the machine tool operators at RBC attend a course taught by William Barkman of Martin Marietta Energy Systems, Inc., of Oak Ridge, Tennessee.

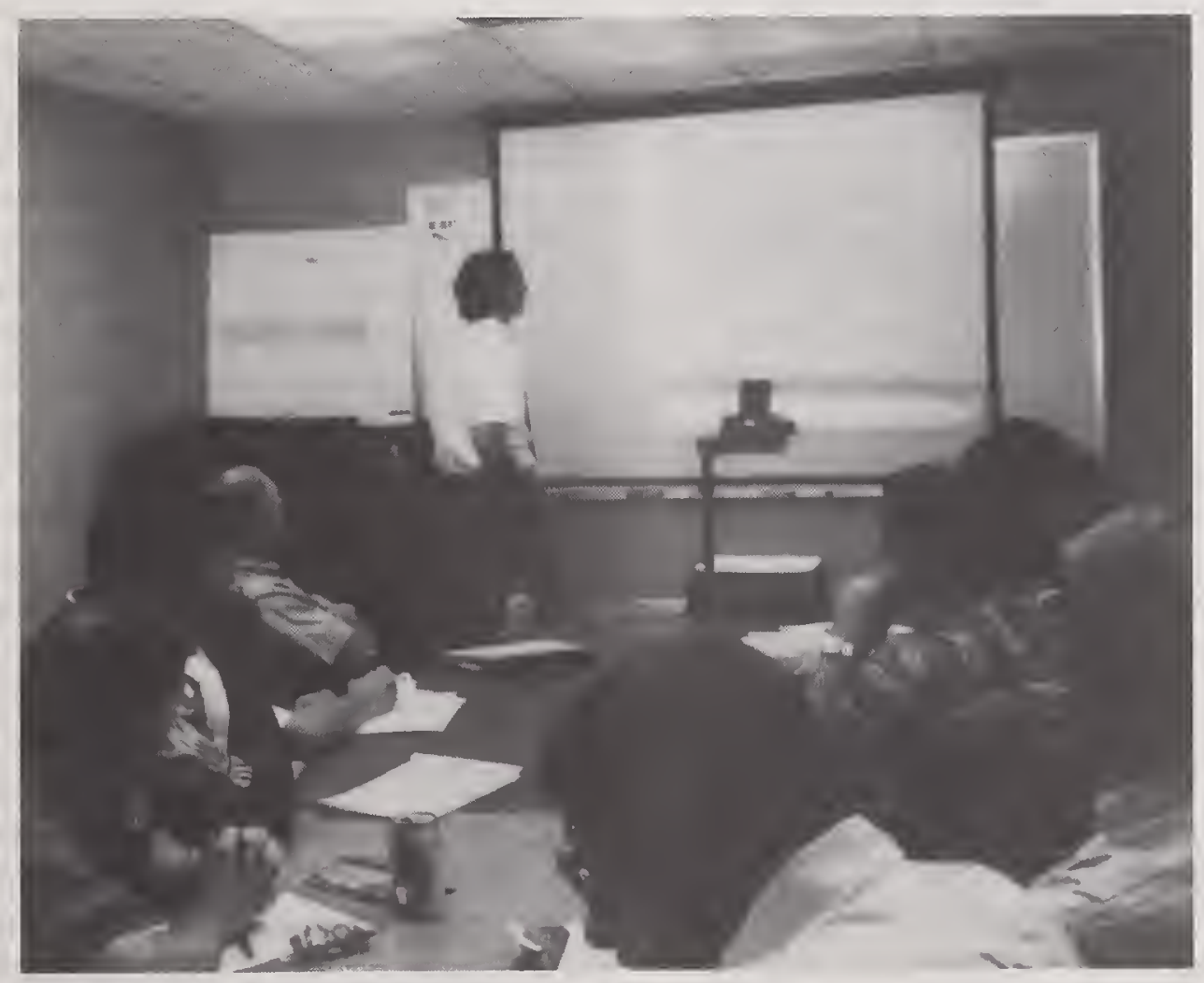

Figure 9. Machine tool operators course on "Deterministic Manufacturing" taught by William Barkman of Martin Marietta Energy Systems of Oak Ridge, Tennessee. As a result of this course, RBC now has a much clearer understanding of the intricacies of the machine tools currently on the plant floor and is in excellent position to begin the next phase of improvements which would be the acquisition of some new CAM-driven machine tools. 
Mr. Barkman's course, entitled "Deterministic Manufacturing," was held at RBC and was well attended by both the machine tool operators and management. The subject of the course involves procedures that can be used to benchmark the characteristics of individual machine tools that are used in the manufacturing process to determine the reproducibility of the machining operations and how various parameters affect the final dimensions of the product. This is a time-consuming process, but once the machine operators have worked out the details for an individual machine, the process can easily be repeated for all the similar machines used in the manufacturing process. Once each machine has been benchmarked, small corrective actions can be implemented while the products are still in the fabrication cycle which take into account small differences inherent in the individual machines. This improvement is not one that is costly in terms of capital equipment outlays. The results, however, should improve the final product.

\section{Carolina Equipment and Supply Company Inc., Charleston, SC}

The Carolina Equipment and Supply Company is a small, family-owned business that specializes in custom-built, high-pressure, industrial cleaning equipment. Its business operations are located in North Charleston, South Carolina. It has been in business for 18 years and currently has 38 employees.

The Carolina Equipment and Supply Company markets a diverse line of high pressure, water-based spray equipment that can be used in a variety of commercial cleaning operations such as removing graffiti from concrete walls, stripping paint from automobiles for repainting, and for removing barnacles from the hulls of ships. The process used is one in which a low volume of water at pressures of up to $80 \mathrm{MPa}$ $\left(12,000 \mathrm{lb} / \mathrm{in}^{2}\right)$ is ejected through a nozzle. Controlled amounts of air and sodium bicarbonate are seeded into the high-pressure stream of water to provide some degree of abrasive action. In addition, the nozzles can be designed to rotate which gives the highpressure water stream a pulsating effect similar to a massage head on a shower. This makes the stream even more effective for cleaning purposes. The end result is a cleaning process that is extremely effective yet not detrimental from an abrasive standpoint (unlike sandblasting, for instance). Since the cleaning equipment is somewhat standardized, it is generally only necessary to adapt the equipment to the new process or application being considered. Most of the equipment packages sold by Carolina Equipment are custom designed and are generally one-of-a-kind custom-built packages. As such, in the process of marketing these packages, the firm typically must build several prototypes to both test equipment and to demonstrate concepts to clients. This can be expensive, especially if after demonstration, the client decides not to go forward with the acquisition of the equipment.

Carolina Equipment and Supply Company was recently approached by a leading South Carolina electronics manufacturer to develop a glass-cleaning system that would replace a current manual cleaning operation. During the manufacturing process involved in the production of some ceramic capacitors, it is necessary to clean the remnants of the previous production cycle from a glass plate that had been used to grow the devices. The current cleaning process being used is a manual cleaning operation that takes as long as 10 to 15 minutes. Furthermore, the situation is such that the process requires a high volume of these plates each day (as many as 3000 per day), leading to a very labor-intensive cleaning process. After studying the situation, Larry Fulmer, president of Carolina Equipment and Supply, and his technical staff designed a high-pressure nozzle system that would perform the desired cleaning operation in approximately ten seconds. The custom-built equipment was fashioned after an automated assembly line process. In the process the plates are placed on a conveyer assembly where they pass over the automated spray cleaning equipment.

Following cleaning, the plates are rinsed, dried, and stacked for reuse in the capacitor fabrication process. Larry Fulmer and his staff felt that the process they had designed would work, but because the project was of such a large magnitude, Carolina Equipment and Supply did not have the available resources to build a full-scale mock up in order to demonstrate feasibility of the process.

Larry Fulmer thought it might be possible to use a CAD system to build 3-dimensional color models to demonstrate the glass-cleaning operation to the electronics manufacturing firm, but he didn't feel he had the necessary expertise to accomplish the task. At this point, he contacted Tom Pennington, a technical specialist with the SMTC in Charleston. Tom thought the idea would be a good way to convey the process to the customer. Tom in turn contacted David Reiling and Roger Hsiao of the SMTC in Columbia. David is a senior technical specialist with the SMTC whose area of specialization is CAD/CAM. Roger Hsiao is an assistant professor in the mechanical engineering department of the University of South Carolina who specializes in CAD. Roger designed a 3-dimensional color model of the cleaning process and equipment as envisioned by the staff at the Carolina Equipment and Supply Co. From a series of these models, he constructed a short tape with a video camera. Larry Fulmer used this videotape to demonstrate to the electronics firm the concepts of the power washing 


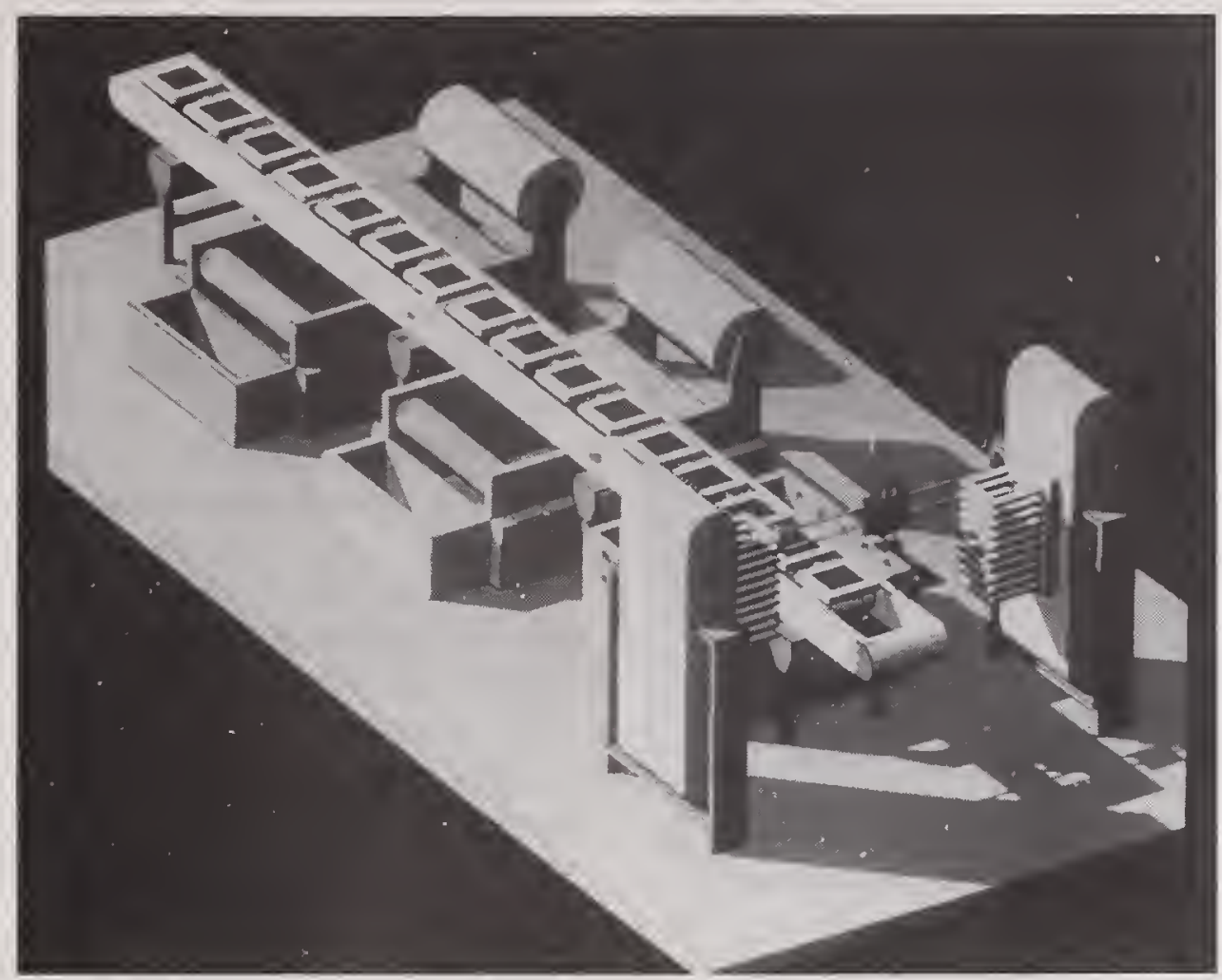

Figure 10. Three-dimensional CAD artist's conception of the high-pressure cleaning equipment that was designed by Carolina Equipment and Supply Company to clean glass plates used in a semiconductor fabrication process.

system that could be used to clean the glass plates. As a result, the Carolina Equipment and Supply Company is currently negotiating a contract worth $\$ 250,000$ for the design and construction of the cleaning equipment.

Larry Fulmer believes that this type of delivery mechanism could be used as a general marketing tool for the type of equipment that his firm manufactures (custom-built, one-of-a-kind pieces of equipment). In addition, the prototyping costs would be cut considerably over trying to develop full-scale mock-ups of proposed cleaning systems. He and his technical staff are currently working with David Reiling who is assisting them with the acquisition, installation, and training of a CAD system that can be used by the Carolina Equipment and Supply Company in future demonstrations.

\section{Doty Scientific Inc, Columbia, SC}

Doty Scientific is a high-technology firm that specializes in a variety of products for the scientific community. It is located in Columbia, South Carolina. It was established in May 1982 and has grown from the original four employees to a company with 50 employees. It has grown at the rate of approximately $30 \%$ per year for the past five years. It specializes in the manufacture of complete sub-assemblies for commercial Nuclear Magnetic Resonance (NMR) spectrometers. This type of spectrometer is routinely used in the fields of organic, physical, and analytical chemistry for the analysis of the molecular structures of many different types of chemical samples ranging from gases to high-temperature solids. The sub-assemblies manufactured by Doty Scientific are uniquely designed to hold solid samples such as organic polymers and various solid substances. They feature air bearings for fast spinning of the sample (up to 25 $\mathrm{kHz}$ ) and have integral heaters and cryogenic cooling coils for performing the analysis at elevated temperatures and cryogenic temperatures. The products manufactured by Doty Scientific are used in the laboratories of DuPont, Dow Chemical, GE, IBM, Bell Labs, Lockheed, Shell, Exxon, Proctor \& Gamble, Ford Motor Company, and virtually all major universities worldwide. Annual sales are currently $\$ 4$ million with $30 \%$ of this being in the international arena.

Doty Scientific's interactions with the Southeast Manufacturing Technology Center (SMTC) is in an area that is totally separate from its highly successful NMR product line. Over the past few years, Doty Scientific has been in the process of developing a line of unique modular MicroTube Strip (MTS) heat exchangers that have extremely high efficiency $(\geqslant 98 \%)$ and relatively low pressure drop. Heat exchange is one of the most fundamental industrial processes. Improvements in the cost and efficiency of this basic process will have a beneficial effect on a wide spectrum of U.S. industries, including cryogenics, air separation, and chemical process industries. The Department of Energy and industrial research laboratories have therefore 


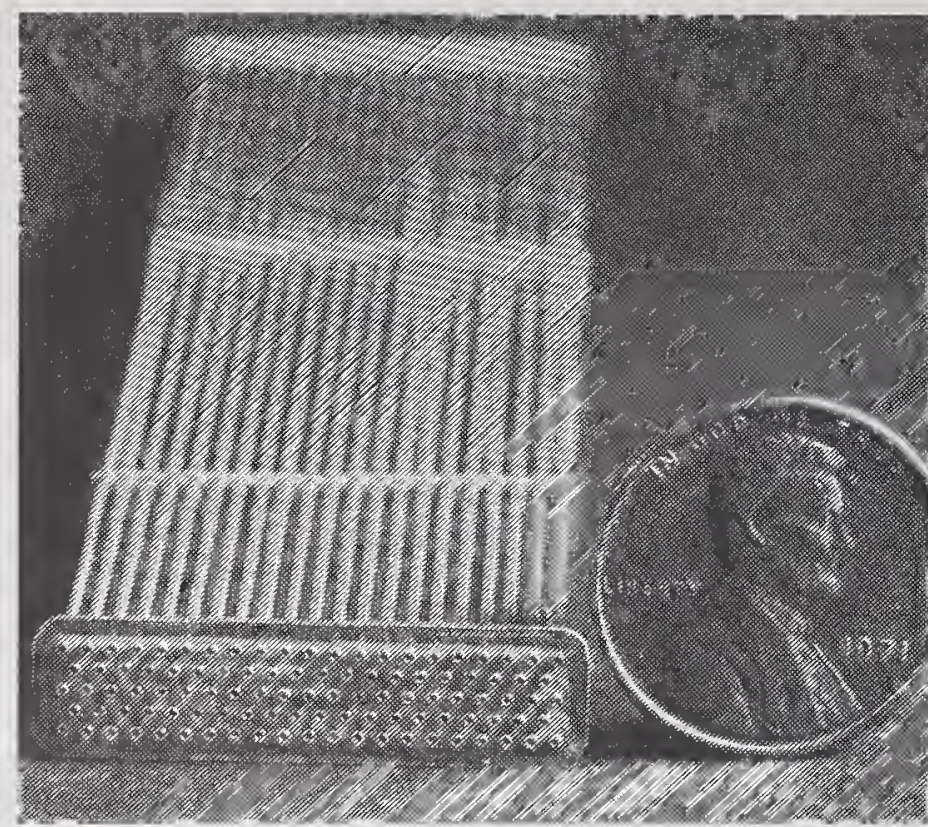

Figure 11. A microtube heat exchanger illustrating the end cap which was produced using the Swiss fineblanking process.

invested considerable effort in developing closedcycle heat engines for automotive use, but these efforts have as yet not been entirely successful due to the high costs of materials and fabrication associated with the production of the heat exchangers. The heat exchangers being developed by Doty Scientific hold promise of being an order of magnitude less expensive to manufacture than the types that are currently on the market.

The MicroTube Strip heat exchanger that Doty is developing consists of an array of several hundred small-diameter stainless steel tubes $(\leqslant 1.0 \mathrm{~mm}$ diameter) which are closely spaced on triangular pitch centers. (See fig. 1.) To form the complete heat exchanger, a number of identical modules each containing several hundred tubes are manifolded together into a heat exchanger bank. The array of tubes are held at the proper separation by spacers along the length of the tubes. On each end a header holds the tubes in place and a weld is made between the header and the tubes. Once this weld is made, a cap is then welded over each end so that gas can flow through the array of tubes. As one might imagine, there are numerous difficulties associated with the construction of such a delicate device that must be manufactured very precisely. For efficient flow across the outer shell, the array of tubes is limited to approximately ten in depth, but the width can be several centimeters. In prototype models the tube spacers and headers have been precisely drilled and reamed on an individual, hole-by-hole basis. Obviously, this is a time-consuming step in the fabrication process and introduces a bottleneck in the fabrication process even if totally automated equipment is used to drill and ream the holes. In order to eliminate this bottle- neck Doty Scientific began to look into alternative processes for the construction of the spacers and headers for the heat exchangers.

For large scale production, a technique that holds the most promise is one called Swiss fineblanking. This is a controlled, cold-flow blanking (punching) process that includes the use of a counterpunch and a high-pressure ring indenter (stripper) which applies sufficient pressure to the metal surfaces near the punch edges to prevent normal and planar deformation of the metal during punching. The technique requires compound dies and triple-action presses, but it results in minimal edge fracturing and deformation. The dies used in this process are fairly expensive, with costs in the $\$ 15,000-\$ 40,000$ price range, so it is not cost effective to test a large number of prototypes and procedures in order to obtain the most optimum fabrication process. In the first attempt at this process, Doty Scientific worked closely with a firm that specializes in the production of dies for the Swiss fineblanking process. The initial die was used to stamp an array of 408 holes in a multiple-hit process. In the ensuing assembly procedure it was found that in some cases the assembly could be done in a straightforward fashion but not on a consistent basis. It was thought that some variations might be occurring in the hole spacings due to stresses which developed in the header strip as a result of using the multiple-hit punching technique. The staff at Doty Scientific was not able to verify this with the measurement devices that they had on the premises. At this point they contacted Dr. Curtis Rhodes, Director of the Advanced Technologies Program of the SMTC. After several conversations with the staff at Doty Scientific, Curtis realized that in order to measure the small variations in the punching process that would present difficulties in the assembly procedure, an extremely good coordinate measuring machine capable of making measurements in the $1-2 \mu \mathrm{m}$ regime would be required. Curtis contacted Dr. Philip Nanzetta, Director of the Manufacturing Technology Program at NIST, to see if it would be possible to have the measurements performed at NIST. Phil talked with the staff in the Dimensional Metrology Group in the Precision Engineering Division at NIST. Jay H. Zimmerman and his co-workers in the Dimensional Metrology Group were in the process of testing and error mapping a new non-contact measuring system which is similar to a coordinate measuring machine. The instrument is state-of-the-art, and it employs a camera-based data gathering unit which uses $20 \mathrm{x}-80 \mathrm{x}$ magnification lenses. The expanded image of the object being measured is displayed on a computer monitor. The system is capable of making measurements on 
the $1.5-2 \mu \mathrm{m}$ scale. Jay measured the hole spacings in the Swiss fineblanked headers and spacers that were fabricated using a multiple-hit technique. The measurements confirmed the suspicions of the staff at Doty Scientific in that the multiple-hit punching process produced variations in the hole spacings that were too large to be acceptable in the assembly procedure although the hole spacing within a given punching was truly impressive with all holes being nicely formed.

The major limitation with the single-hit fineblanking technique is the extreme die stress that ultimately results in die rupture as the relative hole spacing is reduced or the number of rows increased. Based on the results of the NIST measurements, it appears doubtful that the multiple-hit process can be successfully used in production; however, if slightly wider spaced holes are used, a single-hit process appears feasible for the fabrication of the header plates and spacers.

In a separate problem concerning the development of automated procedures for assembling the tube arrays into the spacer and header assemblies, difficulties were encountered in developing the proper amount of thrust needed to force the headers and tube spacers over the tube array. A certain amount of thrust is required to assure the proper assembly of the tubes into the headers and spacers, and this will vary somewhat from one unit to the next. If too much force is used, the modulus of elasticity of the tubes will be exceeded, and the tubes will bend or break instead of being forced through the holes in the headers and spacers. The staff of Doty Scientific again contacted Dr. Curtis Rhodes of the SMTC for assistance with measuring the critical buckling loads for the microtubes being used in the heat exchangers. Dr. Rhodes constructed an apparatus which employed an electronic balance to measure the weight necessary to cause the microtubes to buckle. He tested various lengths of the tubing. Following these experiments, he was able to compare his results with those predicted from the Euler buckling equation. ${ }^{2}$ The results of the experiment agreed quite well with the curve predicted from theory suggesting that for other sized tubes (diameters and lengths) the theoretical equation could be used to determine the buckling loads. For an array of microtubes, the buckling force should scale in a linear fashion, so the thrust of the assembly machines at Doty Scientific can be set accordingly to use a sufficient amount of thrust to force the tube array through the headers and spacers but below the limit that would cause the tubes to buckle.

The two problems with the commercial development of the new MicroTube Strip heat exchanger described above are but a small portion of the many hurdles that Doty Scientific faces in the development of this new product. In addition to the problems described above, automated assembly must be developed, diffusion welding techniques perfected, and eventually the possibility of using new super-alloys investigated. The staff at Doty Scientific are extremely competent, and they hope to have continued beneficial interactions with the SMTC. During the next year or so they should be well on their way toward commercialization of this new product line. If Doty Scientific is successful in this venture, the market for an inexpensive heat exchanger could exceed $\$ 10$ billion during the next 15 years.

${ }^{2}$ Egor P. Popov, "Introduction to Mechanics of Solids," Prentice Hall, Inc. (1968), pp. 515-543. 


\section{Glossary}

CAD $\quad C$ omputer- $A$ ided $D$ esign; the process of constructing engineering drawings using a computer and software rather than a conventional drafting board and instruments.

CAM $\quad C$ omputer- $A$ ided $M$ anufacturing; the process of using a computer and appropriate software to develop instructions for computer-controlled machining (typically a lathe or milling machine) to manufacture a part. All movements of the machine and tool speed are sent by computer instruction directly to the machine.

CAMP $\quad C$ leveland $A$ dvanced $M$ anufacturing $P$ rogram; a not-for-profit organization established in 1984 to offer industry one of the most comprehensive technology development and transfer programs in the United States.

CIM Computer Integrated $M$ anufacturing; a technique of manufacturing where computers are used throughout an integrated manufacturing process.

CNC Computer $N$ umerically $C$ ontrolled; a process of using a computer to control a manufacturing machine, typically a lathe or milling machine, whereby a set of instructions is coded and then downloaded (sometimes punched on a paper tape) and then transferred to the machine to execute.

DXF A graphics format used by a number of $\mathrm{CAD}$ software programs for transferring CAD files.

GLMTC $G$ reat $L$ akes $M$ anufacturing $T$ echnology $C$ enter; one of the three original Manufacturing Technology Centers established in 1989 by the National Institute of Standards and Technology. It is a division of the Cleveland Advanced Manufacturing Program and is located on the campus of the Cuyahoga Community College in Cleveland, Ohio.

ITI Industrial Technology Institute; a notfor-profit organization with a mission to promote the renewal and continuing vitality of North American manufacturing. It was established in 1982 and is headquartered in Ann Arbor, Michigan.

IGES

$I$ nitial $G$ raphics $E$ xchange $S$ pecification; a set of specifications that defines a neutral data format that allows for the digital exchange of information among computer-aided design (CAD) systems.

JIT Just-In-Time; a system of ordering materials and overall method of production used in a manufacturing process where the materials arrive shortly before they are needed thus minimizing the time materials are held in inventory.

KTEC $K$ ansas $T$ echnology $E$ nterprise $C$ orporation; a non-profit corporation established by the state of Kansas in 1987 with a mission to create and maintain employment by fostering innovation, stimulating the commercialization of new technologies, and promoting the creation, growth, and expansion of Kansas enterprises.

LAN $\quad L$ ocal $A$ rea $N$ etwork; an integrated system of hard-wired small computers and an appropriate software package that is used to link the computers together so that messages and data can be transferred throughout the system.

MAMTC $M$ id- $A$ merica $M$ anufacturing $T$ echnology $C$ enter; one of the two new Manufacturing Technology Centers established in 1991 by the National Institute of Standards and Technology. It is a subsidiary of the Kansas Technology Enterprise Corporation, and it is located in Overland Park, Kansas.

MMTC $M$ idwest $M$ anufacturing $T$ echnology $C$ enter; one of the two new Manufacturing Technology Centers established in 1991 by the National Institute of Standards and Technology. It is a subsidiary of the Industrial Technology Institute, and it is located in Ann Arbor, Michigan. 
$M$ anufacturing $R$ esource $F$ acility; a joint venture between Cuyahoga Community College's Unified Technology Center (UTC) and the Cleveland Advanced Manufacturing Program (CAMP). The facility is located on the campus of Cuyahoga Community College in downtown Cleveland, Ohio. It features over $\$ 5$ million worth of the most modern automated machining equipment, computer hardware, and software. The staff at UTC and GLMTC provide small to mid-sized manufacturing companies in the Great Lakes area with hands-on manufacturing demonstrations, training, and education necessary for manufacturing modernization and modern-day competitiveness.

MTC $\quad M$ anufacturing $T$ echnology $C$ enters; a new initiative at the National Institute of Standards and Technology. The charge of the program was to improve U. S. industrial productivity and competitiveness by advancing the technology level of small and medium-sized companies.

MTRF $\quad M$ anufacturing $T$ echnology $R$ esource $F$ acility; a CAD/CAM demonstration facility that is designed to assist small manufacturing firms in their quest for automating their manufacturing facilities. It is located on the campus of Rensselaer Polytechnic Institute (RPI) and is a part of NEMTC. The facility has numerous hardware configurations and software packages available for use by small manufacturing firms to become familiar with current state-of-the-art CAD/CAM techniques.

NEMTC $N$ orth $E$ ast $M$ anufacturing $T$ echnology Center; one of the three original Manufacturing Technology Centers established in 1989 by the National Institute of Standards and Technology. It is located on the campus of Rensselaer Polytechnic Institute in Troy, New York.

NIST $\quad N$ ational Institute of $S$ tandards and Technology; a part of the Department of Commerce which was formerly the National Bureau of Standards. The name change occurred in 1988 as part of the Omnibus Trade and Competitiveness Act.
PC-AT Personal Computer-A dvanced Technology; a series of computers pioneered by International Business Machines (IBM) that originally employed Intel-80286 microprocessors. Many companies have adopted this technology and built computers that employ the same architecture. Eventually this computer series was upgraded and now consists of 80386 and 80486 processors also.

SMTC Southeast $M$ anufacturing Technology Center; one of the three original Manufacturing Technology Centers established in 1989 by the National Institute of Standards and Technology. It is located on the campus of the University of South Carolina with additional facilities at the technical colleges spread throughout the state.

SIC Standard Industrial Classification; a system of industrial classification established by the Federal Government and used to categorize businesses by type of economic activity. The codes are published in the Standard Industrial Classification Manual published by the Executive Office of the President, Office of Management and Budget.

TECnet Technologies for $E$ ffective $C$ ooperation network; in 1989, NEMTC formalized arrangements for the establishment of a satellite operation in Massachusetts to develop a network of metalworking firms in Hampden County, for the purpose of identifying and providing group services. The Massachusetts Manufacturing Resource Center at Tufts University serves as the administrator and has established the computer hub, with organization of training activities being coordinated by the Machine Action Project (MAP) in Springfield, Massachusetts.

UTC Unified $T$ echnology $C$ enter; an economic development resource established by the Cuyahoga Community College and the Cleveland Advanced Manufacturing Program in Cleveland, Ohio, in 1986 to provide business and industry with the education and training programs needed to stay competitive. 



\section{BIBLIOGRAPHIC DATA SHEET}

1. PUBLICATION OR REPORT NUMBER

NIST/SP 830

2. PERFORMING ORGANIZATION REPORT NUMBER

3. PUBLICATION DATE

February 1992

4. TITLE AND SUBTITLE

The Manufacturing Technology Centers Program: A Sampling of Individual Case Histories

AUTHOR(S)

Richard Suenram

6. PERFORMING ORGANIZATION (IF JOINT OR OTHER THAN NIST, SEE INSTRUCTIONS)

U.S. DEPARTMENT OF COMMERCE

NATIONAL INSTITUTE OF STANDARDS AND TECHNOLOGY

GAITHERSBURG, MD 20899

7. CONTRACT/GRANT NUMBER

8. TYPE OF REPORT AND PERIOD COVERED

Final

9. SPONSORING ORGANIZATION NAME AND COMPLETE ADDRESS (STREET, CITY, STATE, ZIP)

Same as Item \# 6

10. SUPPLEMENTARY NOTES

DOCUMENT DESCRIBES A COMPUTER PROGRAM; SF-185, FIPS SOFTWARE SUMMARY, IS ATTACHED.

11. ABSTRACT (A 200-WORD OR LESS FACTUAL SUMMARY OF MOST SIGNIFICANT INFORMATION. IF DOCUMENT INCLUDES A SIGNIFICANT BIBUOGRAPHY OR LITERATURE SURVEY, MENTION IT HERE.)

This NIST Special Publication introduces the NIST Manufacturing Technology Centers (MTC) Program and the organizations which serve as its regional centers. The purpose of the program is to speed the transfer of advanced manufacturing technology to U.S. industry, especially small-and medium-sized firms, through a series of regional technology centers. This brochure highlights a variety of interactions that the regional centers have had with manufacturing firms. These interactions are presented in case history format.

12. KEY WORDS (6 TO 12 ENTAIES; ALPHABETICAL ORDER; CAPITALIZE ONLY PROPER NAMES; AND SEPARATE KEY WORDS BY SEMICOLONS) case histories; Great Lakes Manufacturing Technology Center; Mid-America Manufacturing Thchnolugy Center; Nidwest Nanufacturing Techiology Center; ivsT Wanufacturing Techrology Centers; Northeast Manufacturing Technology Center; Southeast Manufacturing Technology Center

\section{AVAILABILITY}

UNLIMITED

FOR OFFICIAL DISTRIBUTION. DO NOT RELEASE TO NATIONAL TECHNICAL INFORMATION SERVICE (NTIS).

ORDER FROM SUPERINTENDENT OF DOCUMENTS, U.S. GOVERNMENT PRINTING OFFICE, WASHINGTON, DC 20402.

ORDER FROM NATIONAL TECHNICAL INFORMATION SERVICE (NTIS), SPRINGFIELD, VA 22161.
14. NUMBER OF PRINTED PAGES

25

15. PRICE

\footnotetext{
ELECTRONIC FORM U. S. Government Printing Office: $1992-311-943$ (62608)
} 


\section{Technical Publications}

\section{Periodical}

Journal of Research of the National Institute of Standards and Technology-Reports NIST research and development in those disciplines of the physical and engineering sciences in which the Institute is active. These include physics, chemistry, engineering, mathematics, and computer sciences. Papers cover a broad range of subjects, with major emphasis on measurement methodology and the basic technology underlying standardization. Also included from time to time are survey articles on topics closely related to the Institute's technical and scientific programs. Issued six times a year.

\section{Nonperiodicals}

Monographs-Major contributions to the technical literature on various subjects related to the Institute's scientific and technical activities.

Handbooks - Recommended codes of engineering and industrial practice (including safety codes) developed in cooperation with interested industries, professional organizations, and regulatory bodies.

Special Publications - Include proceedings of conferences sponsored by NIST, NIST annual reports, and other special publications appropriate to this grouping such as wall charts, pocket cards, and bibliographies.

Applied Mathematics Series - Mathematical tables, manuals, and studies of special interest to physicists, engineers, chemists, biologists, mathematicians, computer programmers, and others engaged in scientific and technical work.

National Standard Reference Data Series - Provides quantitative data on the physical and chemical properties of materials, compiled from the world's literature and critically evaluated. Developed under a worldwide program coordinated by NIST under the authority of the National Standard Data Act (Public Law 90-396). NOTE: The Journal of Physical and Chemical Reference Data (JPCRD) is published bi-monthly for NIST by the American Chemical Society (ACS) and the American Institute of Physics (AIP). Subscriptions, reprints, and supplements are available from ACS, 1155 Sixteenth St., NW., Washington, DC 20056.

Building Science Series-Disseminates technical information developed at the Institute on building materials, components, systems, and whole structures. The series presents research results, test methods, and performance criteria related to the structural and environmental functions and the durability and safety characteristics of building elements and systems.

Technical Notes-Studies or reports which are complete in themselves but restrictive in their treatment of a subject. Analogous to monographs but not so comprehensive in scope or definitive in treatment of the subject area. Often serve as a vehicle for final reports of work performed at NIST under the sponsorship of other government agencies.

Voluntary Product Standards-Developed under procedures published by the Department of Commerce in Part 10, Title 15, of the Code of Federal Regulations. The standards establish nationally recognized requirements for products, and provide all concerned interests with a basis for common understanding of the characteristics of the products. NIST administers this program as a supplement to the activities of the private sector standardizing organizations.

Consumer Information Series-Practical information, based on NIST research and experience, covering areas of interest to the consumer. Easily understandable language and illustrations provide useful background knowledge for shopping in today's technological marketplace. Order the above NIST publications from: Superintendent of Documents, Government Printing Office, Washington, DC 20402.

Order the following NIST publications - FIPS and NISTIRs - from the National Technical Information Service, Springfield, VA 22161.

Federal Information Processing Standards Publications (FIPS PUB)-Publications in this series collectively constitute the Federal Information Processing Standards Register. The Register serves as the official source of information in the Federal Government regarding standards issued by NIST pursuant to the Federal Property and Administrative Services Act of 1949 as amended, Public Law 89-306 (79 Stat. 1127), and as implemented by Executive Order 11717 (38 FR 12315, dated May 11, 1973) and Part 6 of Title 15 CFR (Code of Federal Regulations).

NIST Interagency Reports (NISTIR)-A special series of interim or final reports on work performed by NIST for outside sponsors (both government and non-government). In general, initial distribution is handled by the sponsor; public distribution is by the National Technical Information Service, Springfield, VA 22161, in paper copy or microfiche form. 


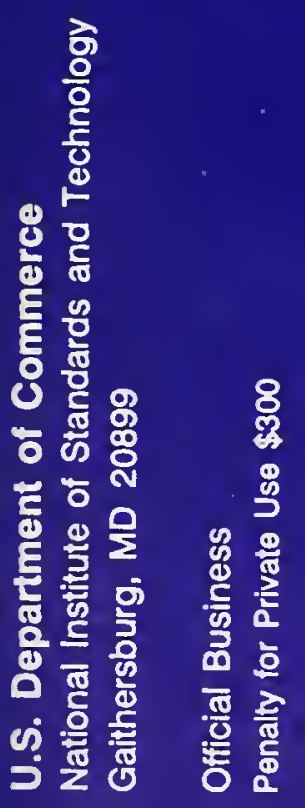

